NEXT Ion Thruster Thermal Model

Jonathan L. Van Noord

Glenn Research Center, Cleveland, Ohio

November 2010 


\section{NASA STI Program . . . in Profile}

Since its founding, NASA has been dedicated to the advancement of aeronautics and space science. The NASA Scientific and Technical Information (STI) program plays a key part in helping NASA maintain this important role.

The NASA STI Program operates under the auspices of the Agency Chief Information Officer. It collects, organizes, provides for archiving, and disseminates NASA's STI. The NASA STI program provides access to the NASA Aeronautics and Space Database and its public interface, the NASA Technical Reports Server, thus providing one of the largest collections of aeronautical and space science STI in the world. Results are published in both non-NASA channels and by NASA in the NASA STI Report Series, which includes the following report types:

- TECHNICAL PUBLICATION. Reports of completed research or a major significant phase of research that present the results of NASA programs and include extensive data or theoretical analysis. Includes compilations of significant scientific and technical data and information deemed to be of continuing reference value. NASA counterpart of peer-reviewed formal professional papers but has less stringent limitations on manuscript length and extent of graphic presentations.

- TECHNICAL MEMORANDUM. Scientific and technical findings that are preliminary or of specialized interest, e.g., quick release reports, working papers, and bibliographies that contain minimal annotation. Does not contain extensive analysis.

- CONTRACTOR REPORT. Scientific and technical findings by NASA-sponsored contractors and grantees.
- CONFERENCE PUBLICATION. Collected papers from scientific and technical conferences, symposia, seminars, or other meetings sponsored or cosponsored by NASA.

- SPECIAL PUBLICATION. Scientific, technical, or historical information from NASA programs, projects, and missions, often concerned with subjects having substantial public interest.

- TECHNICAL TRANSLATION. Englishlanguage translations of foreign scientific and technical material pertinent to NASA's mission.

Specialized services also include creating custom thesauri, building customized databases, organizing and publishing research results.

For more information about the NASA STI program, see the following:

- Access the NASA STI program home page at http://www.sti.nasa.gov

- E-mail your question via the Internet to help@ sti.nasa.gov

- Fax your question to the NASA STI Help Desk at $443-757-5803$

- Telephone the NASA STI Help Desk at 443-757-5802

- Write to: NASA Center for AeroSpace Information (CASI) 7115 Standard Drive Hanover, MD 21076-1320 
NEXT Ion Thruster Thermal Model

Jonathan L. Van Noord

Glenn Research Center, Cleveland, Ohio

Prepared for the

43rd Joint Propulsion Conference and Exhibit

cosponsored by the AIAA, ASME, SAE, and ASEE

Cincinnati, Ohio, July 8-11, 2007

National Aeronautics and

Space Administration

Glenn Research Center

Cleveland, Ohio 44135 
Level of Review: This material has been technically reviewed by technical management.

Available from

NASA Center for Aerospace Information

7115 Standard Drive

Hanover, MD 21076-1320
National Technical Information Service 5301 Shawnee Road Alexandria, VA 22312

Available electronically at http://gltrs.grc.nasa.gov 


\title{
NEXT Ion Thruster Thermal Model
}

\author{
Jonathan L. Van Noord \\ National Aeronautics and Space Administration \\ Glenn Research Center \\ Cleveland, Ohio 44135
}

\begin{abstract}
As the NEXT ion thruster progresses towards higher technology readiness, it is necessary to develop the tools that will support its implementation into flight programs. An ion thruster thermal model has been developed for the latest prototype model design to aid in predicting thruster temperatures for various missions. This model is comprised of two parts. The first part predicts the heating from the discharge plasma for various throttling points based on a discharge chamber plasma model. This model shows, as expected, that the internal heating is strongly correlated with the discharge power. Typically, the internal plasma heating increases with beam current and decreases slightly with beam voltage. The second is a model based on a finite difference thermal code used to predict the thruster temperatures. Both parts of the model will be described in this paper. This model has been correlated with a thermal development test on the NEXT Prototype Model 1 thruster with most predicted component temperatures within 5 to $10^{\circ} \mathrm{C}$ of test temperatures. The model indicates that heating, and hence current collection, is not based purely on the footprint of the magnet rings, but follows a 0.1:1:2:1 ratio for the cathode-to-conical-to-cylindrical-tofront magnet rings. This thermal model has also been used to predict the temperatures during the worst case mission profile that is anticipated for the thruster. The model predicts ample thermal margin for all of its components except the external cable harness under the hottest anticipated mission scenario. The external cable harness will be re-rated or replaced to meet the predicted environment.
\end{abstract}

\section{Introduction}

Spaceflight hardware requires a combination of testing and modeling to simulate the extreme operational environment. Initially, thermal and mechanical models are used to design the hardware to meet environmental requirements. Once the hardware is built, thermal vacuum and mechanical testing occurs to provide thermal data to validate the design. Thermal testing is also necessary for the development of a high fidelity thermal model with minimized uncertainties associated with contact resistances and surface emissivities. Once the thermal model has been calibrated to test data, it can be used to predict various mission and spacecraft interface scenarios. This thermal model is then used to predict the extreme temperatures anticipated for the hardware. These temperatures can be used in cyclic thermal vacuum testing to demonstrate that hardware will survive and operate under these conditions. This paper will focus on the development of a thermal model for the NEXT ion thruster.

Thermal vacuum testing and modeling has occurred on several previous generations of ion thrusters including $20-\mathrm{cm}$ mercury ion thrusters (Ref. 1), 30-cm mercury ion thrusters (including the J-series thruster) (Refs. 2 to 5), and 30-cm xenon ion thrusters (including the NSTAR/DS-1 thruster) (Refs. 6 to 11). NASA's Evolutionary Xenon Thruster (NEXT) is the latest generation xenon ion thruster, with a beam extraction diameter of $36-\mathrm{cm}$. This thruster is under development and the latest hardware is a prototype model (PM) ion thruster. Thermal testing and related data have been acquired on engineering model (EM) and prototype model thrusters. The thermal differences between the two have been significant, with the most significant modification being a higher emissivity tiodize coating to the PM thruster. An early thermal model of the NEXT thruster was built to aid in the design of the PM thruster and was part of the rationale that led to the use of higher emissivity coatings.

A higher fidelity thermal model of the NEXT PM ion thruster has been developed and is presented in this document. This thermal model was validated through the thermal testing of the PM1 thruster under 
various throttling levels and environmental conditions during the Thermal Development Test (TDT) (Ref. 12). This model has also been used to predict thruster temperatures of various mission scenarios, and supports assessment of the thermal impact of any design changes and spacecraft integration. The results from the thermal model have also been used to establish the thermal environmental requirements necessary for testing.

This document will detail the model used to predict the heating from the plasma, the comparison of the finite difference thermal thruster model to TDT results (Ref. 12), and the maximum predicted flight thruster temperatures.

\section{Thermal Model of the NEXT PM Ion Thruster}

The thermal model consists of two different types of models that are necessary to predict the thruster temperatures. The first model predicts the heat flux from the thruster plasma during operation at various throttling points. This model is based on a discharge plasma model that assumes the discharge plasma is uniform within the discharge chamber. The results from the plasma model heat fluxes are used as an input into the second model. This second model is built using a finite-difference, commercially available code that predicts the thruster temperatures based on the thruster thermal conductivity and surface radiation properties and also predicts the environmental heat fluxes based on orbital parameters.

Initially, a detailed derivation of the plasma heating model will be described along with the results for various throttling levels ranging from the lowest to highest throttling power. This plasma model is also useful for identifying the dominant mechanisms for discharge losses. Next, the finite difference model will be described and the plasma model will be used in conjunction with the results from the thermal development test to validate the model. A facility related plasma heating effect will also be described and its impact on the thruster evaluated. Finally, a prediction of the highest temperatures anticipated during any of the design reference missions is presented.

\section{Model of Heating From Internal Plasma}

The plasma heating model is based on two related discharge chamber plasma models and is a derivative of the plasma heating model that was originally created for the NSTAR program (Refs. 13, 14, and 15) This and the other referenced models assume a 0-D, bulk homogeneous discharge plasma. Within the discharge plasma, it is assumed that the electron temperature, the plasma potential, the various densities, and the various velocities are constant and uniform. The model is based on the conservation of mass and energy.

\section{Derivation of Equations}

Neutral and Primary Electron Velocities.-Knowledge of the mean neutral speed, $v_{o}$, present in the discharge chamber is essential to determine the various plasma densities. The neutral speed in Equation (1) is determined based on the temperature of the neutral gas, which is assumed to be the same as the discharge chamber walls (typically 150 to $300^{\circ} \mathrm{C}$ ), and follows a Maxwellian distribution.

$$
v_{o}=\sqrt{\frac{8 k T_{n}}{\pi M_{X e}}}
$$

In order to determine the average velocity of the primary electrons, it is necessary to calculate the energy of these electrons in the bulk plasma. The primary electron energy, $V_{p e}$, is determined by taking

$$
V_{p e}=V_{D}-V_{C}+V_{A}
$$




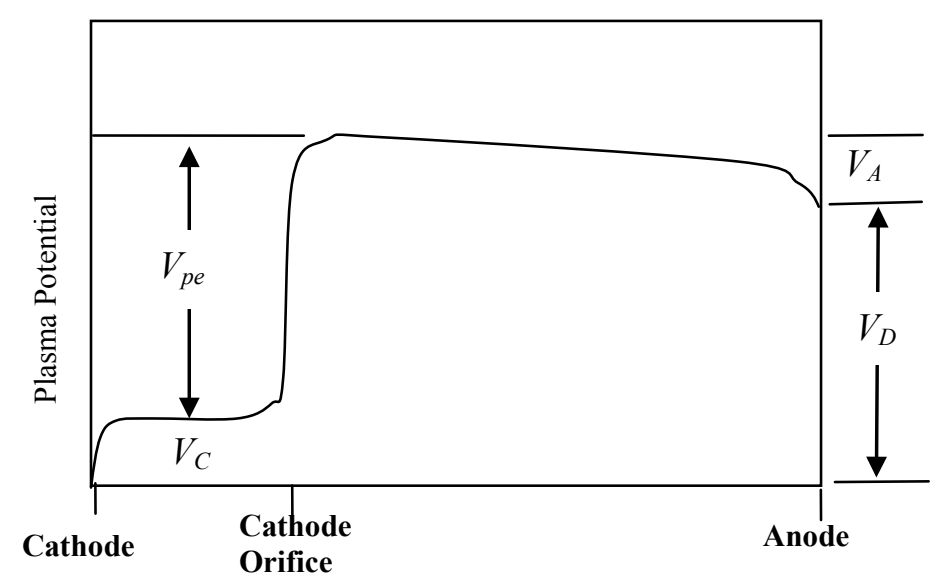

Figure 1.-Discharge chamber plasma potential variations from cathode to anode.

the discharge voltage, $V_{D}$, and subtracting off the cathode fall voltage, $V_{C}$, and adding the anode fall voltage, $V_{A}$ (see Eq. 2). It is assumed that the primaries enter the bulk plasma with this energy. The plasma potential is depicted in Figure 1. A further discussion of the plasma potential can be found in Reference 14. The plasma is generally positive of the anode. Reference 14 includes a term for the plasma potential fall between the cathode orifice and the anode sheath. For simplicity, this model will account for that fall included in the anode fall term. The model of the discharge plasma is calculated separately from the plasma within the cathode and it is assumed that the primary electrons originate at the cathode fall.

Once the potential drop is derived, the velocity of the mono-energetic primary electrons, $v_{p e}$, is calculated by simply relating the final kinetic energy to the initial potential energy and is described in Equation (3).

$$
v_{p e}=\sqrt{\frac{2 e V_{p e}}{M_{e}}}
$$

Plasma and Neutral Densities. - The mass utilization efficiency, $\eta_{m}$, is defined as the ratio of ions leaving in the beam to the number of xenon atoms introduced into the chamber and is given in Equation (4). The mass flow rate, $\dot{m}$, is frequently given in sccm and the value $4.5 \times 10^{17} e$ converts the mass flow of sccm to an ampere equivalent.

$$
\eta_{m}=\frac{I_{B}}{\dot{m} 4.5 \times 10^{17} e}
$$

The density of the neutrals, $n_{o}$, can be determined by simply equating the neutral influx and the atoms leaving the thruster through the optics in the form of neutrals and ions. This is derived in Reference 14 and given in Equation (5).

$$
n_{o}=\frac{4 I_{B}\left(1-\eta_{m}\right)}{v_{o} e A_{g} \Phi_{a g o} \eta_{c} \eta_{m}}
$$

The primary electron density, $n_{p-}$, was calculated in both References 13 and 14 . From Reference 14 the derived equation is given in Equation (6) and is based on the assumption that the mean time for a collision between a primary electron and a neutral gas atom is much shorter than the mean time for the primary electron to be thermalized by the plasma electrons or the ballistic confinement time before a primary electron is lost to the anode. 


$$
n_{p-}=\frac{I_{e} v_{o} A_{g} \Phi_{a g o} \eta_{c} \eta_{m}}{4 V \sigma_{T} v_{p e} I_{B}\left(1-\eta_{m}\right)}=\frac{I_{e}}{e n_{o} V \sigma_{T} v_{p e}}
$$

The plasma ion density, $n_{+}$, is calculated based on the beam current and the transparency, $\Phi_{i}$, and area of the grids, $A_{g}$, to extract the ions from the discharge plasma. This relationship is detailed in Equation (7) (Refs. 13 and 16).

$$
n_{+}=\frac{2 I_{B}}{v_{b} e A_{g} \Phi_{i}}
$$

The Maxwellian electron density, $n_{m}$, can be calculated simply based on the assumption that the discharge plasma is quasi-neutral and shown in Equation (8).

$$
n_{m-}=n_{+}
$$

Plasma Electron Temperature.-It is necessary to calculate the plasma electron temperature in order to predict the power from the electrons to various surfaces. The most effective way to calculate this temperature has been through an iterative method. The iterative approach is depicted in Figure 2.

Initially, the Maxwellian electron temperature, $T_{m}$, is estimated. This temperature is then used to calculate Bohm velocity, $v_{b}$, and hence the ion density, $n_{+}$, in Equation (7). The estimated electron temperature and corresponding densities are then used to calculate the Maxwellian electron rate factor for ionization neutral atoms, $Q_{o}{ }^{+}$(the product of the ionization collisional cross section averaged over the Maxwellian electron energy distribution).

The Maxwellian electron rate factor for ionizing neutral atoms can be calculated from engine parameters by equating the total ions produced in the plasma to those lost from the plasma. The total ions produced in the plasma, $I_{p l}{ }^{+}$, result from interaction of neutrals with Maxwellian electrons, $I_{m-}{ }^{+}$in Equation (9), and primary electrons, $I_{p-}{ }^{+}$in Equation (10), and is calculated using Equation (11). The ion production is determined by neutral density, $n_{o}$, the primary electron density, $n_{p-}$, the Maxwellian electron density, $n_{m-}$, the volume of the ion production region, $V$, and the respective rate factors, $\operatorname{Pr}_{o}^{+}$and $Q_{o}^{+}$.

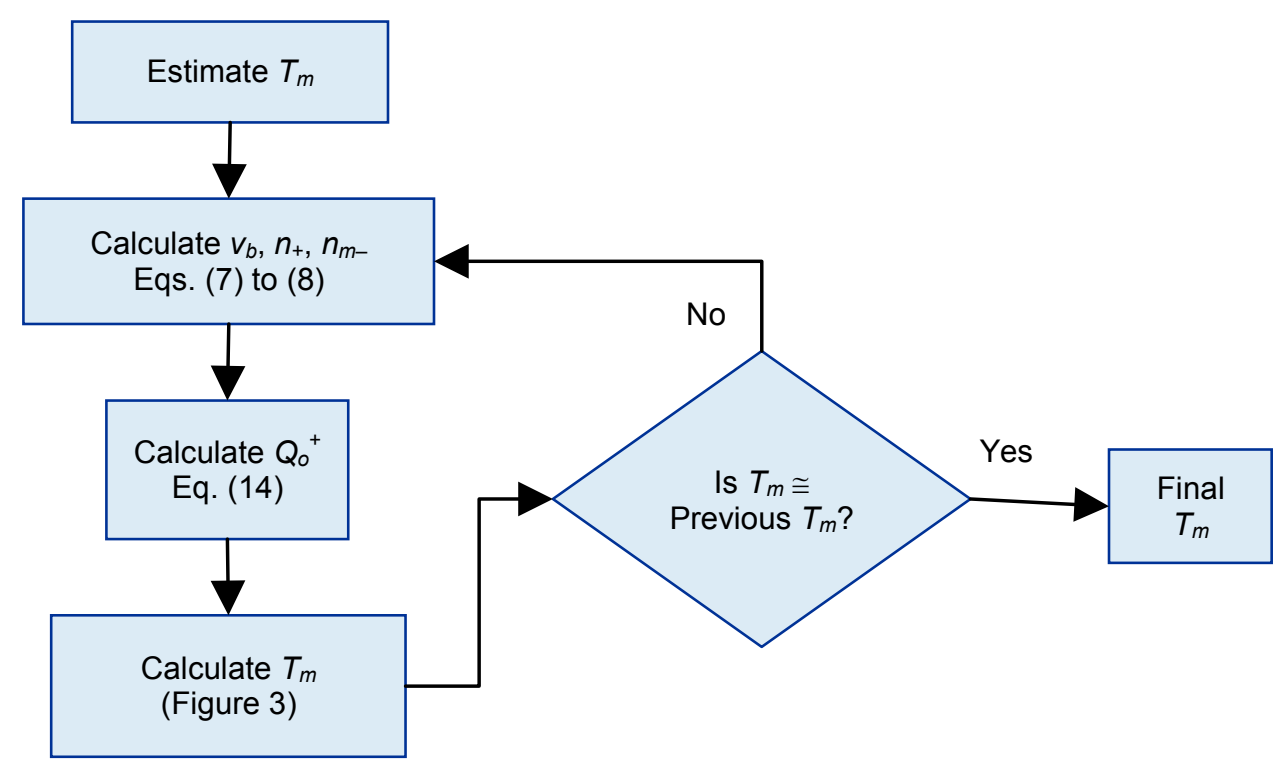

Figure 2.-Flow chart describing the derivation of the plasma electron temperature. 
The Maxwellian electron rate factor for ionizing neutral atoms can be calculated from engine parameters by equating the total ions produced in the plasma to those lost from the plasma. The total ions produced in the plasma, $I_{p l}{ }^{+}$, result from interaction of neutrals with Maxwellian electrons, $I_{m-}{ }^{+}$in Equation (9), and primary electrons, $I_{p-}{ }^{+}$in Equation (10), and is calculated using Equation (11). The ion production is determined by neutral density, $n_{o}$, the primary electron density, $n_{p-}$, the Maxwellian electron density, $n_{m-}$, the volume of the ion production region, $V$, and the respective rate factors, $\operatorname{Pr}_{o}^{+}$and $Q_{o}^{+}$.

$$
\begin{gathered}
I_{m-}^{+}=n_{o} n_{m-} e V<\sigma_{+} v_{m-}>=n_{o} n_{m-} e V Q_{o}^{+} \\
I_{p--}^{+}=n_{o} n_{p-} e V<\sigma_{+} v_{p e}>=n_{o} n_{p-} e V P r_{o}^{+} \\
I_{p l}^{+}=I_{m-}^{+}+I_{p-}^{+}=e n_{o} V\left(n_{m-} Q_{o}^{+}+n_{p-} P r_{o}^{+}\right)
\end{gathered}
$$

The ion loss rate, $I_{l}^{+}$, is calculated using the Bohm current (Eq. (12)). As shown in Equation (13), the total ion loss area, $A_{i}$, is the sum of the grid area, $A_{g}$, the keeper area, $A_{k}$, and the anode area modified (see Ref. 14) to account for the magnetic fields and ambipolar flow at the anode.

$$
\begin{gathered}
I_{l}^{+}=\frac{1}{2} n_{i} e v_{b} A_{i} \\
A_{i}=A_{g}+A_{k}+A_{h a}+A_{s a} f_{c}
\end{gathered}
$$

Once equating the ion production in the plasma given in Equation (11) with the ion loss out of the plasma in Equation (12), the Maxwellian ionization rate factor can be determined from the discharge plasma properties using an assumed electron temperature. Equation (14) shows this derived relation.

$$
Q_{o}^{+}=\frac{v_{b} A_{i}}{2 n_{o} V}-\frac{n_{p-}}{n_{m-}} \operatorname{Pr}_{o}^{+}
$$

Once the reaction rate coefficient for xenon is calculated in Equation (14) from thruster-based parameters, a corresponding electron temperature can be determined from the experimentally derived cross sections that were determined independent of any thruster (Ref. 17). Figure 3 shows this empirically-derived relationship between the Maxwellian reaction rate factor and the electron temperature. As shown in

Figure 2, if the new temperature derived from Figure 3 is sufficiently different than the previous electron temperature, it is used to recalculate the densities in Equations (7) and (8) and the process is repeated until the electron temperature is constant throughout the model.

\section{Ion and Electron Currents}

(a) Excitation of Neutrals and Ions from Primary Electrons.-A substantial amount of energy in a xenon ion thruster is lost to the excitation of neutrals and some ions. In this model it is assumed that the excitation is only from the primary electrons. The rate at which neutrals are excited is related to the cathode emission current, $I_{e}$, which can be found by subtracting the screen grid current, $I_{s g}$, from the measured discharge current, $I_{D}$, (See Eq. (15)).

$$
I_{e}=I_{D}-I_{s g}
$$




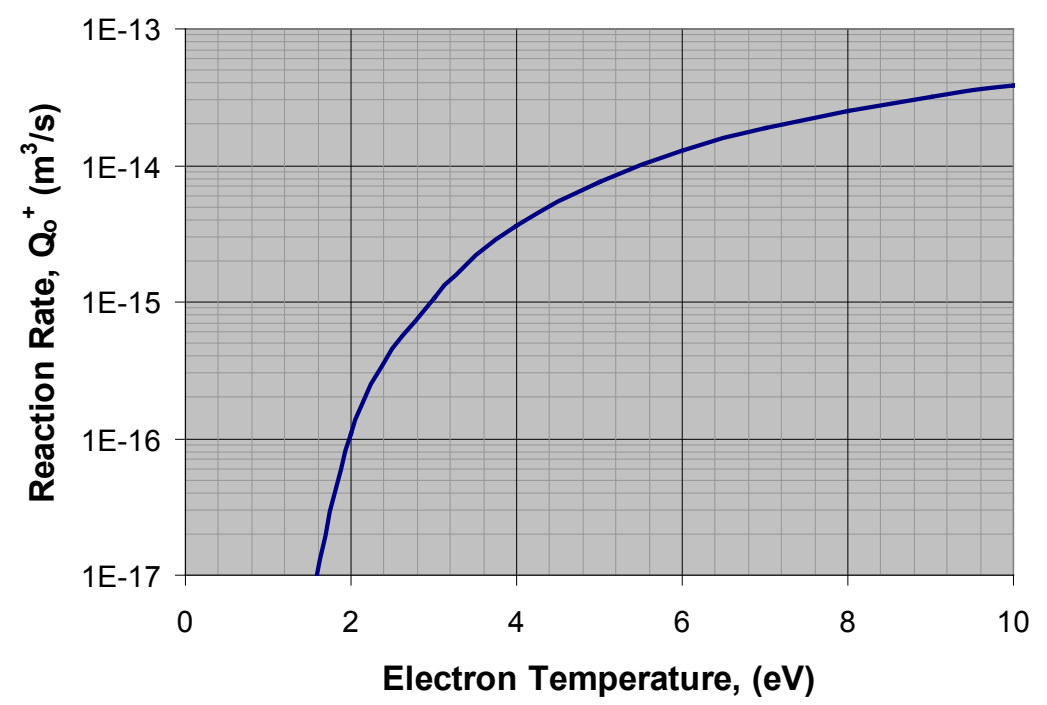

Figure 3.-Graph depicting xenon ionization reaction rate factor variation with electron temperature.

The rate at which the excitation of neutrals, $I_{n^{*}}$, and ions, $I_{+*}$, occurs is based on the probability that the emitted electrons result in an excitation event. As shown in Equations (16) and (17), this is determined by the respective cross sections, $\sigma_{p^{*}}$ or $\sigma_{p^{+*}}$, the densities and the average length a primary electron travels before it is collected, $L_{p-}$.

$$
\begin{gathered}
I_{n}^{*}=I_{e}\left(1-\exp \left(-\sigma_{p^{*}} n_{o} L_{p-}\right)\right) \\
I_{+}^{*}=I_{e}\left(1-\exp \left(-\sigma_{p+*} n_{i} L_{p-}\right)\right)
\end{gathered}
$$

(b) Screen Grid.-The screen grid ion current, $I_{s g}{ }^{+}$, is determined from the beam current, $\underline{I}_{B}$, and measured ion transparency of the grids, $\Phi_{i}$, and given in Equation (18). Electron current to the screen grid, $I_{s g}{ }^{-}$, is then calculated by subtracting the measured screen grid, $I_{s g}$, from the calculated ion current (see Eq. (19)).

$$
\begin{gathered}
I_{s g}^{+}=\frac{I_{B}\left(1-\Phi_{i}\right)}{\Phi_{i}} \\
I_{s g}^{-}=I_{s g}^{+}-I_{s g}
\end{gathered}
$$

(c) Keeper.-Previous work has correlated average beam current density and the average keeper ion current density for the NSTAR and NEXT ion thrusters (Ref. 18). The empirical relationship described in that reference was used to derive the ion keeper current, $I_{k}^{+}$(Eq. (20)). The electron current to the keeper, $I_{k}^{-}$, is a sum of the ion current and the current that flows through the resister, $\Omega_{\mathrm{k}}$, between the keeper and anode, and is shown in Equation (21).

$$
I_{k}^{+}=\left(\frac{1.167 I_{B}}{A_{g}}+0.283\right) A_{k}
$$




$$
I_{\bar{k}}=I_{k}^{+}+\frac{V_{D}-V_{k}}{\Omega_{k}}
$$

(d) Anode.-The primary electron current to the anode, $I_{a n}{ }^{p-}$, can be calculated based on the probability that the primary electron will undergo a collision. As shown in Equation (22), $I_{a n}{ }^{p-}$ is calculated from the emission current, $I_{e}$, the total ionization and excitation cross section, $\sigma_{t}$, the neutral density, $n_{o}$, and the average length traveled by a primary electron before collection by the anode, $L_{p-\text {. }}$

$$
I_{a n}^{p-}=I_{e} \exp \left(-\sigma_{T} n_{o} L_{p-}\right)
$$

The ion current to the anode, $I_{a n}{ }^{+}$, can be calculated by balancing the total ions produced, $I_{p l}{ }^{+}$ (Eq. (11)), to those lost out of the plasma. The discharge plasma ions will be lost either to the anode, beam, screen grid, or keeper. It is assumed that any ions created in the discharge cathode remain in the cathode and are separate from the discharge plasma. Thus, Equation (23) can be used to determine the ion current to the anode.

$$
I_{a n}^{+}=I_{p l}^{+}-I_{B}-I_{s g}^{+}-I_{k}^{+}
$$

The Maxwellian electron current to the anode, $I_{a n}{ }^{m-}$, can be determined based on the current measured through the discharge power supply $\left(I_{D}\right)$, the ion current to the anode $\left(I_{a n}{ }^{+}\right)$, an electron for each beam ion that exits the discharge chamber $\left(I_{B}\right)$, and the primary electrons that are collected $\left(I_{a n}{ }^{p-}\right)$. Figure 4 depicts the electron current flow that corresponds to Equation (24). Note that this includes the electron current that corresponds to the beam ions and is not accounted for in the discharge power supply.

$$
I_{a n}^{m-}=I_{D}+I_{a n}^{+}+I_{B}-I_{a n}^{p-}
$$

\section{Power Deposition}

(a) Ionization and Excitation.-The average power used to ionize each beam ion or to excite the neutrals or ions can be found by multiplying the respective currents times their threshold energies (Eqs. (25) to (27)). For xenon, the ionization threshold, $U_{+}$, is $12.13 \mathrm{eV}$, the excitation of neutrals from ground state, $U_{n^{*}}$, is $8.3 \mathrm{eV}$, and the excitation of ions, $U_{i^{*}}$, is $11.27 \mathrm{eV}$. The power it takes to ionize a beam ion leaves the discharge chamber with the beam ion and does not deposit its energy on the thruster. However,

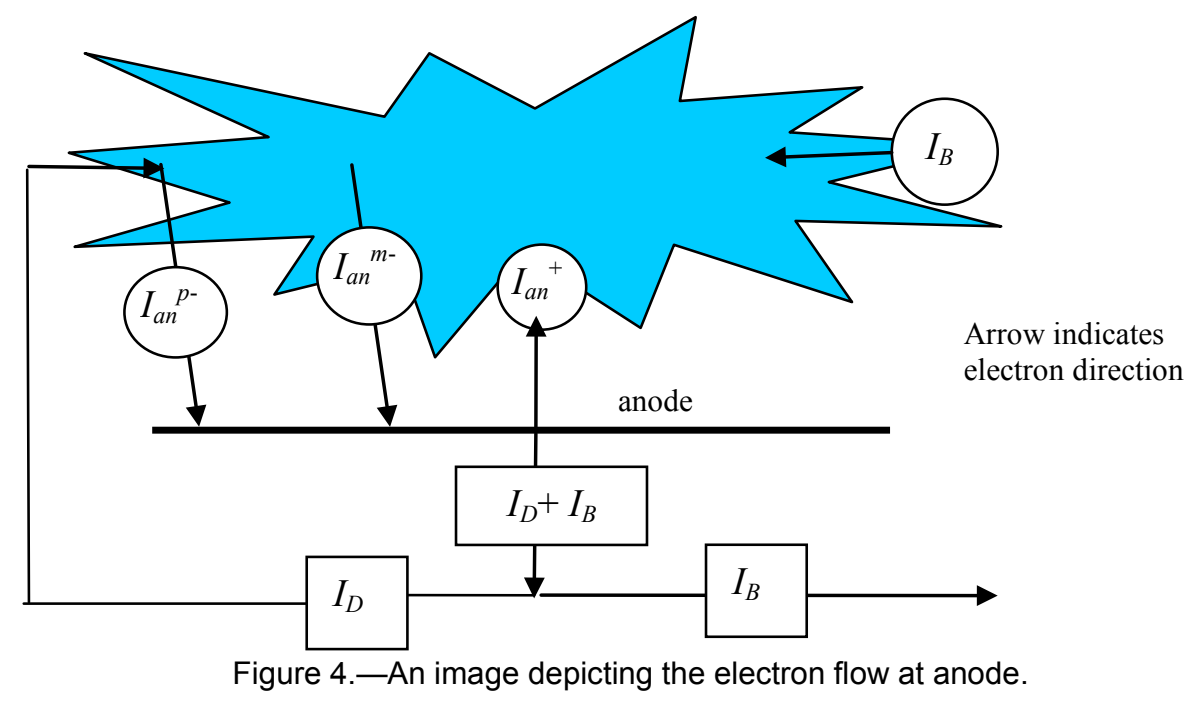


it is assumed that the power it takes to excite a neutral or ion is contained and radiated inside the discharge chamber. If the neutral is left with higher thermal energy from the excitation event, it is assumed to eventually deposit that energy on the discharge chamber surface. This power deposition from excitation is assumed to be uniformly distributed over the discharge chamber surfaces and equal to the power used for excitation. The calculation of the energy to the individual discharge chamber surfaces will be simply the fraction of its surface area to the total discharge chamber surface area, $A_{d c}$, as shown in Equation (28) where $A_{a n}$ is the area of the anode, $A_{g}$ is the area of the optics, and $A_{k}$ is the area of the keeper. The power deposited to the grids will be proportional to their open area and is described in a later section.

$$
\begin{gathered}
P_{b}^{+}=I_{b} U_{+} \\
P_{n}^{*}=I_{n}^{*} U_{n^{*}} \\
P_{i}^{*}=I_{i}^{*} U_{i^{*}} \\
A_{d c}=A_{a n}+A_{g}+A_{k}
\end{gathered}
$$

(b) Anode.-The anode is heated by several mechanisms. Power is deposited from primary electrons, $P_{a n}{ }^{-}$, Maxwellian electrons, $P_{a n}{ }^{m-}$, ions, $P_{a n}{ }^{+}$, and radiated energy from the excited ions and neutrals, $P_{a n}{ }^{*}$. It is assumed that, except for $P_{a n}{ }^{*}$, the power is deposited only on the magnets. The initial assumption is that the total power deposited is uniformly distributed based on the linear length of the magnet rings along the circumference of the discharge chamber. The power from the primary electrons is the total current of the primary electrons to the anode times the anode work function, $\phi_{a n}$, plus the potential between where the electrons originated and the anode (Eq. (29)). In this case that potential is the difference between the discharge potential, $V_{D}$, and the cathode fall voltage, $V_{c}$.

$$
P_{a n}^{p-}=I_{a n}^{p-}\left(\phi_{a n}+\left(V_{D}-V_{C}\right)\right)
$$

The discharge plasma is assumed to be positive relative to the anode (see Figure 1), so the power from the Maxwellian electrons, $P_{a n}{ }^{m-}$, is determined by their temperature, $T_{m}$, and the anode work function.

$$
P_{a n}^{m-}=I_{a n}^{m-}\left(\phi_{a n}+5 / 2 T_{m}\right)
$$

The power deposited from an ion neutralizing on the anode is determined by the fall voltage, $V_{A}$, the ion thermal temperature (assumed to be the same as the neutral temperature, $T_{n}$ ), the ionization energy, $U_{+}$, and the anode work function as the ion extracts the electron and neutralizes. If the ion temperature is a factor of 10 higher than $5 k T_{n} / 2 e$, it will not significantly change the result of this equation since $\mathrm{V}_{\mathrm{A}}$ and $U_{+}$are typically at least an order of magnitude larger in value.

$$
P_{a n}^{+}=I_{a n}^{+}\left(V_{A}+\frac{5 k T_{n}}{2 e}+U_{+}-\phi_{a n}\right)
$$

The radiated energy from the plasma is evenly distributed over the anode surface area, $A_{a n}$, and is based on the fraction of that surface area versus the total discharge chamber visible surface areas, $A_{d c}$, as shown in Equation (32).

$$
P_{a n}^{*}=\frac{A_{a n}}{A_{d c}}\left(P_{n}^{*}+P_{i}^{*}\right)
$$


(c) Keeper.-The heating of the discharge cathode keeper from the plasma ions, $P_{k}^{+}$, is determined as given in Equation (33) by the ion current, $I_{k}^{+}$, the plasma potential, $V_{D^{+}} V_{A}$, the keeper potential, $V_{k}$, the ion/neutral temperature, $T_{n}$, the ionization potential, $U_{+}$, and the keeper work function, $\phi_{k}$.

$$
P_{k}^{+}=I_{k}^{+}\left(\left(V_{D}+V_{A}-V_{k}\right)+\frac{5 k T_{n}}{2 e}+U_{+}-\phi_{k}\right)
$$

The plasma is positive relative to the keeper, so it is only the most energetic plasma electrons that heat the keeper. Equation (34) is the same form as Equation (30) and the heating, $P_{k}^{-}$, is based on the plasma electron current to the keeper, $I_{k}^{-}$, the keeper work function, $\phi_{k}$, and the plasma electron temperature, $T_{m}$.

$$
P_{k}^{-}=I_{k}^{-}\left(\phi_{k}+5 / 2 T_{m}\right)
$$

Just as with the anode, the heat absorbed from the radiating excited species, $P_{k}{ }^{*}$, is based on the fraction of the keeper area, $A_{k}$, to the total discharge chamber area, $A_{d c}$.

$$
P_{k}^{*}=\frac{A_{k}}{A_{d c}}\left(P_{n}^{*}+P_{i}^{*}\right)
$$

(d) Screen Grid.-The screen grid is heated by the ions drawn to the optics, but not extracted out of the optics. Since the plasma is positive relative to the screen grid the power deposited, $P_{s g}{ }^{+}$, is determined by the ion screen grid current, $I_{s g}{ }^{+}$, the potential difference between the plasma and the grids, $V_{D}+V_{A}$, the ion/neutral temperature, $T_{n}$, the ionization potential and the screen grid work function, $\phi_{s g}$. Equation (36) shows the power from the ions impacting the screen grid.

$$
P_{s g}^{+}=I_{s g}^{+}\left(\left(V_{D}+V_{A}\right)+\frac{5 k T_{n}}{2 e}+U_{+}-\phi_{s g}\right)
$$

Just as in the previous cases for heating from the plasma electrons, the power is determined by the electron screen grid current, $I_{s g}{ }^{-}$, the screen grid work function, $\phi_{s g}$, and the plasma electron temperature, $T_{m}$ (Eq. (36)).

$$
P_{s g}^{-}=I_{s g}^{-}\left(\phi_{s g}+5 / 2 T_{m}\right)
$$

The power radiated from the plasma to the screen grid is calculated as before and is shown in Equation (38). The area of the screen grid is calculated using the screen grid open area fraction, $\Phi_{s g o}$, and the area of the ion grids, $A_{g}$.

$$
P_{s g}^{*}=\frac{\left(1-\Phi_{s g o}\right) A_{g}}{A_{d c}}\left(P_{n}^{*}+P_{i}^{*}\right)
$$

(e) Accelerator Grid.-The accelerator grid is heated primarily from the charge-exchange ions and the energy radiated from the plasma in the discharge chamber. The power deposited from the ion impact, $P_{a g}{ }^{+}$, is a product of the charge-exchange ion current, $I_{a g}{ }^{+}$, and the sum of the accelerator fall, $V_{a g}$, which is generally the potential the accelerator grid is measured at, the ion/neutral temperature, $T_{n}$, the ionization potential, $U_{+}$, and the accelerator grid work function, $\phi_{g}$, which is usually the same as the screen grid work function since they are generally the same material. 


$$
P_{a g}^{+}=I_{a g}^{+}\left(V_{a g}+\frac{5 k T_{n}}{2 e}+U_{+}-\phi_{a g}\right)
$$

The accelerator grid is partially shielded from the plasma radiation by the screen grid. This shielding results in the area of the grid to be modified by both the screen grid open area fraction, $\Phi_{s g o}$, and the accelerator grid open area fraction, $\Phi_{\text {ago }}$, in order to determine the power radiated from the plasma to the accelerator grid, $P_{a g}{ }^{*}$.

$$
P_{a g}^{*}=\frac{\left(\Phi_{s g o}-\Phi_{a g o}\right) A_{g}}{A_{d c}}\left(P_{n}^{*}+P_{i}^{*}\right)
$$

(f) Cathode Loss. - Generally, cathode inserts tend to act like fixed temperature devices. That is, for a given current required, the insert will be at a given temperature regardless of losses out of the cathode (to an extent). The equation describing the relationship between the electron current emitted from the entire insert, $I_{\text {ins }}$, and the local insert temperature, $T_{i n s}$, is given in Equation (41) and is known as the RichardDushman equation. The Schottky effect is neglected since it will lower the work function on the order of $0.1 \mathrm{eV}$ and this is well within the uncertainty of the work function value.

$$
I_{\text {ins }}=\int A_{R} T_{i n s}^{2} \exp \left(\frac{-\phi_{\text {ins }} k}{T_{\text {ins }}}\right) d A
$$

A detailed thermal/plasma model of the cathode is described in Reference 15 that includes radiation heat transfer, convection from the gas, conduction along the insert and cathode tube, ohmic heating of the cathode, and heating from the plasma. However, a simple model that considers mainly the thermal conduction along the insert is sufficient to predict the peak temperature and gradient along the insert for a given current (Ref. 19). Equation (42) defines the temperature gradient in the insert based on modeling it using conduction heat transfer. It requires as estimate of the losses out of the insert, $Q_{i n s}$, in order to attain the gradient.

$$
\frac{d T_{\text {ins }}}{d x}=\frac{Q_{\text {ins }}}{K_{\text {ins }} A_{\text {ins } c s}}
$$

The insert thermionic emission current, $I_{i n s}$, is related to the cathode emission, $I_{e}$, by the relation described in Equation (43). The amount of electrons leaving the cathode, $I_{e}$, is equal to those emitted through thermionic emission and those freed through ion neutralization on the surface, $I_{c}^{+}$.

$$
I_{e}=I_{i n s}+I_{c}^{+}
$$

The heating of the insert is from the ions that recombine on the insert surface. The power out of the insert is primarily through the cathode thermal heat loss, $Q_{i n s}$, and the cooling from the thermionic electrons. This power balance is given in Equation (44).

$$
I_{c}^{+}\left(V_{c}+\frac{5 k T_{i n s}}{2 e}+U_{+}-\phi_{i n s}\right)=Q_{i n s}+I_{i n s}\left(\phi_{i n s}+\frac{5 k T_{I n s}}{2 e}\right)
$$

Generally, the greater the losses are out of the insert into the cathode, the greater the temperature differential will be from the front to the back of the insert. Equations (41) to (44) can be used to determine the temperature for the insert for a given emission current with an estimation of cathode thermal loss, $Q_{\text {ins }}$. So the heating from the plasma to the insert and cathode is very dependent on the thermal design of the cathode and its losses. Typical thermal losses out of an insert are around $15 \mathrm{~W}$. This value can be 
confirmed from a thermal model of a specific cathode. For the finite difference thermal model presented in the later sections, the peak temperature predicted is used as the boundary condition and not a heat flux.

\section{Discharge Power}

The model presented is also iterated until the calculated discharge power is equal to the measured discharge power, $P_{d c}$. Often the ion loss area, $\mathrm{A}_{\mathrm{i}}$, is adjusted during the iteration because it is one of the terms with the largest uncertainty. Equation (45) provides the sum of all the losses present relevant to the discharge power supply. The multiplier $\left(1-I_{B} / I_{a n}{ }^{m-}\right)$ is used to subtract off the Maxwellian electrons associated with the production of beam ions. These Maxwellians heat the anode, but are processed through the beam power supply and not the discharge power supply.

$$
P_{d c}=P_{b}^{+}+P_{n}^{*}+P_{i}^{*}+P_{a n}^{+}+P_{a n}^{m-}\left(1-\frac{I_{B}}{I_{a n}^{m-}}\right)+P_{a n}^{p-}+P_{k}^{+}+P_{k}^{-}+P_{s g}^{+}+P_{s g}^{-}+Q_{i n s}
$$

\section{Prediction of Internal Plasma Heating for the NEXT PM Thruster}

The NEXT PM1 thruster was used in the thermal development test (Ref. 12). The goal of this test was to yield temperature data for the thruster to validate and improve the thermal model. Thruster operational data were taken and used as inputs into the plasma model to derive the estimates for plasma induced thruster heating. Input parameters with a degree of uncertainty, such as ion loss area, are varied such that the predicted discharge losses are consistent with the measured discharge power supply. A typical output of the plasma heating model is shown in Figure 5.

The Maxwellian electron temperature is one of the intermediate parameters predicted by the model. For all of the cases examined, this value is typically predicted to be between 2 and $3 \mathrm{eV}$. Measurements of the electron temperature in the bulk plasma of a NEXT thruster have been 3 to $7 \mathrm{eV}$ (Ref. 20). The similarity between the predicted and measured values indicates that the model is producing reasonable plasma predictions.

Plasma heating predictions were derived for various thruster operating conditions based on the thermal development test thruster performance. These predictions are given in Table 1. Generally, the heating of the thruster is highly dependent on the beam current and increases as the beam current increases. At a specific beam current, the heating does not change drastically with beam voltage. It is also interesting to note that while discharge power includes the power to produce the beam ions, which does not result in thruster heating, the heating from the Maxwellian electrons associated with the beam ions offsets the power due to beam ion production such that the total heating of the discharge chamber is approximately equal to the discharge power measured. As with the discharge power, generally for a given beam current, the power deposited increases as the beam voltage decreases. This would indicate that the hottest thermal case is when the thruster is at its highest beam current and lowest beam voltage.

\section{Finite Difference NEXT PM Thruster Model}

\section{Model Description}

The finite difference model has been built using commercially available thermal software. There were 2497 nodes used along with 121 conductors for modeling contact resistance or insulators. An image of the model is shown in Figure 6. This model included many of the thruster components including the discharge cathode assembly, discharge chamber, magnet rings, accelerator and screen grid optics, neutralizer cathode assembly, gimbal pads, plasma screen, and front mask. 


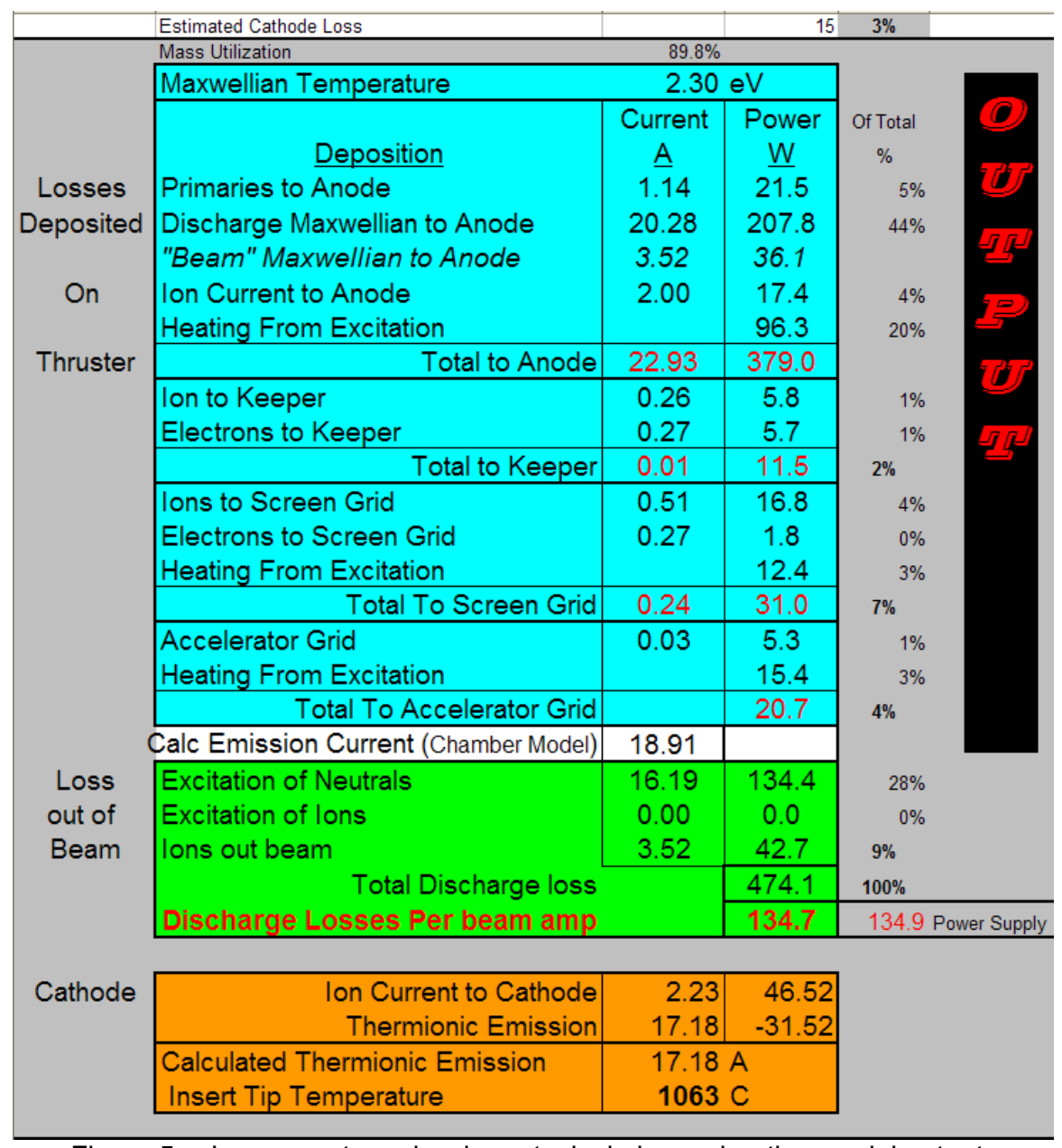

Figure 5.-Image capture showing a typical plasma heating model output.

TABLE 1.-THE HEATING VALUES PREDICTED PRIOR TO TESTING TO NEXT PM THRUSTER

\begin{tabular}{|l|c|c|c|c|c|c|}
\hline Beam voltage (V) & 679 & 1179 & 1800 & 1179 & 1179 & 1800 \\
\hline Beam current (A) & 1.2 & 1.2 & 1.2 & 2.0 & 3.52 & 3.52 \\
\hline Discharge power-power supply (W) & 271 & 243 & 234 & 335 & 475 & 434 \\
\hline Discharge power-model prediction (W) & 273 & 245 & 238 & 335 & 474 & 449 \\
\hline To anode (W) & 235 & 208 & 201 & 278 & 379 & 357 \\
\hline To keeper (W) & 5.1 & 5 & 5 & 6.9 & 11.5 & 11.4 \\
\hline To screen grid (W) & 9.9 & 9.4 & 9.3 & 16.9 & 31 & 29.7 \\
\hline To accelerator grid (W) & 4.5 & 4.5 & 4.9 & 9.0 & 21 & 20.2 \\
\hline Out of cathode (W) & 15 & 15 & 15 & 15 & 15 & 15 \\
\hline Total plasma heating (W) & 270 & 242 & 235 & 326 & 458 & 433 \\
\hline
\end{tabular}



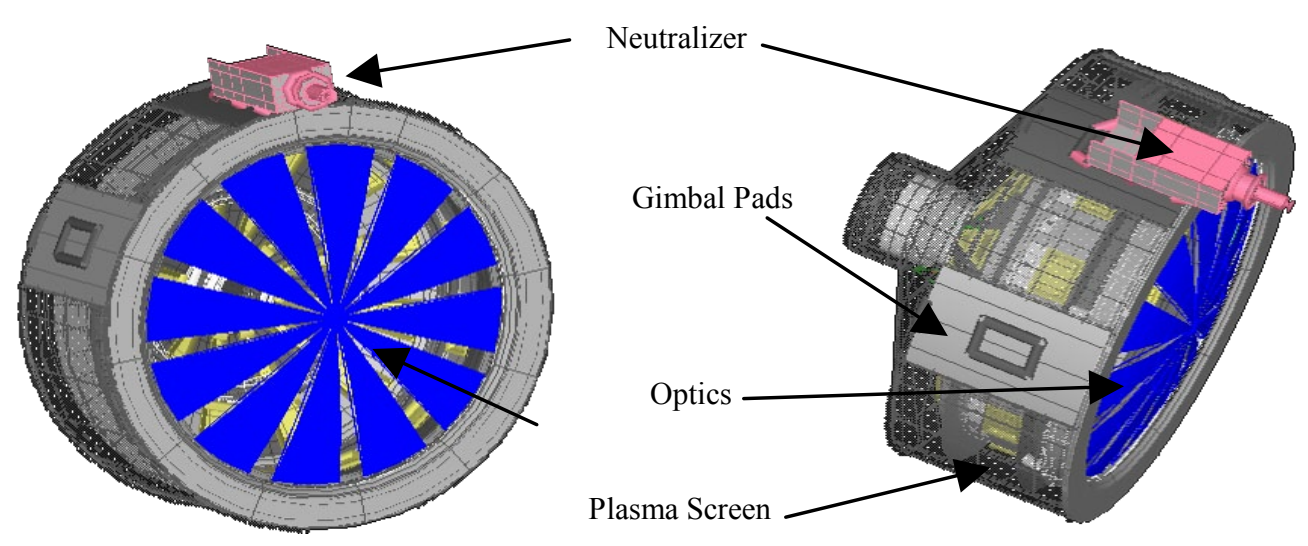

Figure 6.-An image showing the NEXT PM thruster thermal model geometry.

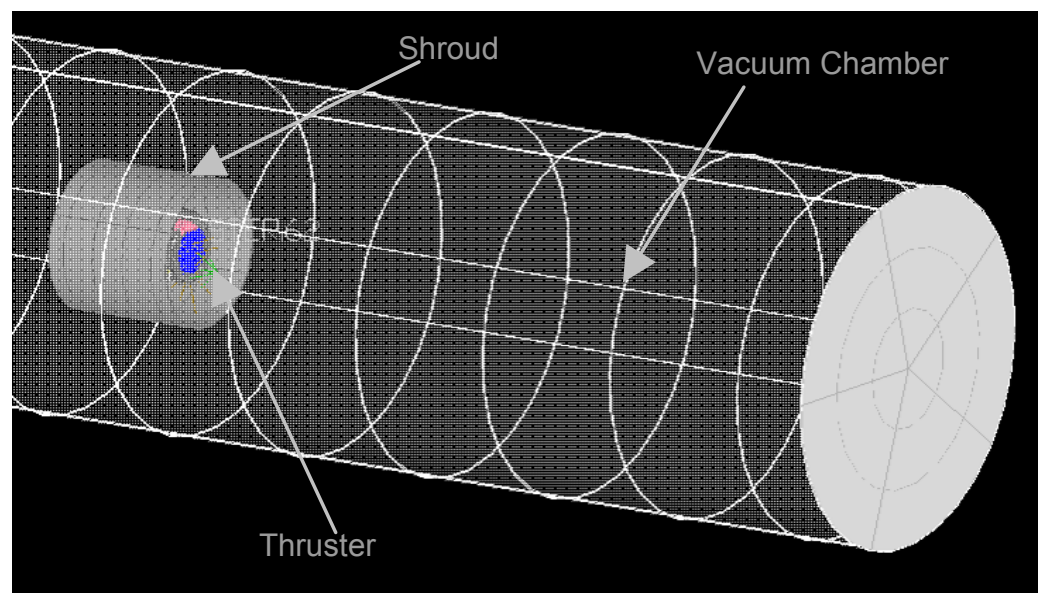

Figure 7.-A graphic showing the thermal model of the thruster during the thermal development test.

\section{Validation of Model to PM1 Thermal Development Test}

This model along with the prediction of heating from plasma was used to predict the temperatures demonstrated during the thermal development test. As typical with thermal models, some of the contact resistances and emissivities were adjusted to attain better correlation with the test data. Contact resistances are dependent on a number of factors, such as the type of mating materials, how thick these materials are, what torque a fastener is under, and the roughness of the surfaces in contact. So these are typically estimated and then calibrated through experimentation, as was done here. Some of the emissivities were adjusted since experimental data was not available for all the materials and their surface finishes. Most of the thruster surfaces have been grit-blasted or have had some texturing for sputter retention, which affects their optical properties.

The test facility was also built into the model. As seen in Figure 7, the thruster was enclosed in a shroud that could be cooled via liquid nitrogen. Quartz lamps were used to provide additional environmental heat, but when they were used, most of their power went to heating the shroud. This meant that when the thruster was heated using the lamps, a majority of the heat flux came from the shroud in the infrared wavelength. The shroud contained several thermocouples that were used to set the shroud temperature in the model as boundary conditions. The vacuum chamber also had a few thermocouples that were used to establish its temperature in the model. 


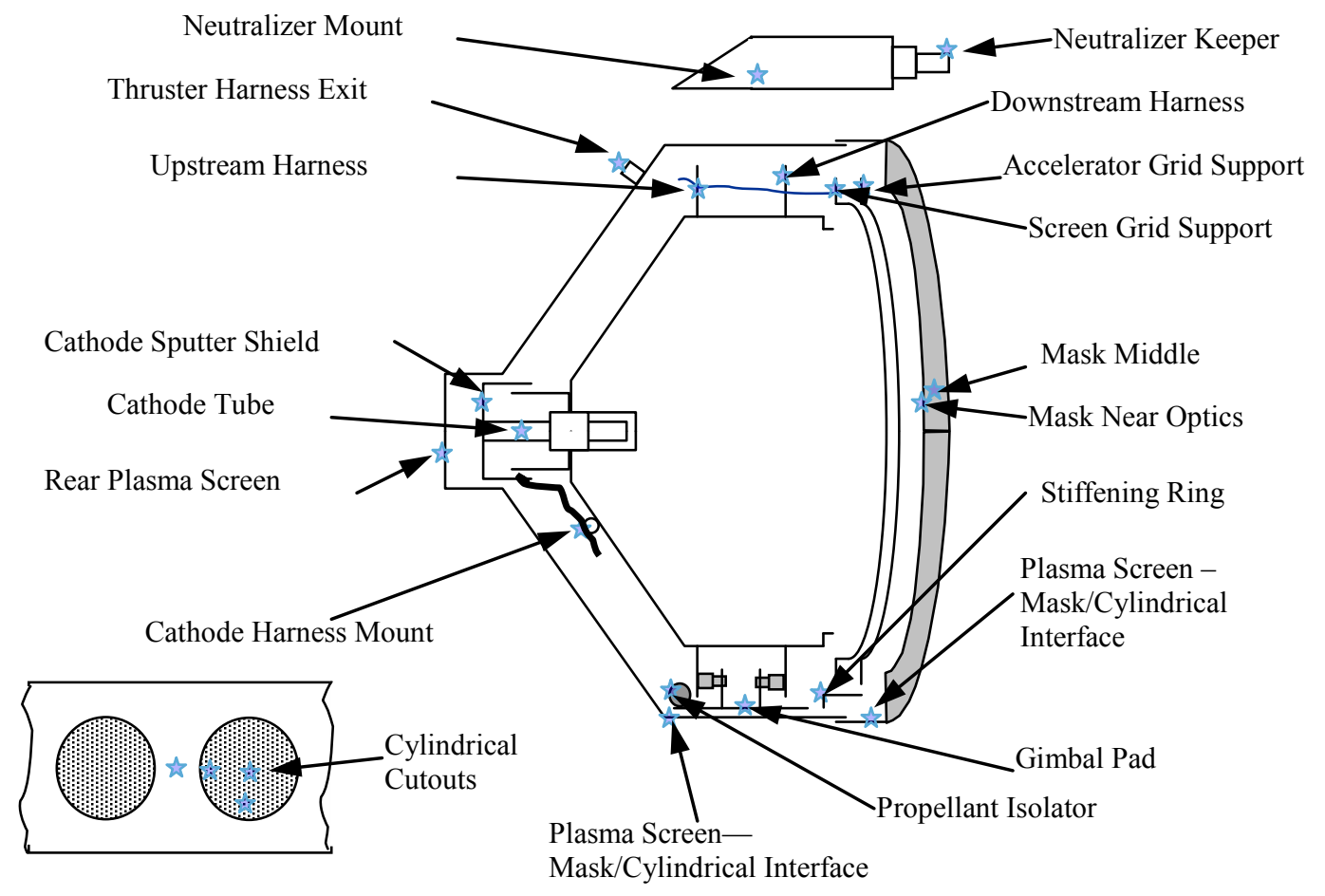

Figure 8.-A schematic showing the thermocouple locations on the NEXT PM1 thruster during the TDT.

The thruster was outfitted with a significant number of thermocouples. The thermocouple locations are shown in Figure 8. Several of the thermocouple radial locations listed had additional thermocouples on the same component, but at a different azimuthal location (e.g. on the middle of the mask, there was a thermocouple near the neutralizer and opposite the neutralizer). These were used to capture any asymmetries that might be present. There were a total of 34 thermocouples on the thruster. Each gimbal pad had an additional pair that were used to measure the change in temperature across a gimbal attachment and, hence, the conducted heat loss out of the gimbal pads. This heat loss out of the gimbal pad was typically 0.4 to $0.7 \mathrm{~W}$, so for the model, these interfaces were modeled as having no conductive losses out of the thruster.

A comparison of the test data to the thermal model predictions is shown in Table 2 and Table 3 . The thruster was modeled under conditions where the shroud was not actively cooled or heated. Predicted temperatures were typically within $10{ }^{\circ} \mathrm{C}$ of the test data representing a good correlation. Locations with larger discrepancies included the downstream harness, the cathode tube, the cylindrical magnet rings, near the discharge chamber cut-outs, and the plasma screen. At the cathode tube location, there is a large temperature gradient, so the discrepancy is likely due to precise location of the thermocouple versus the resolution of the model. The rest of the discrepancies were likely the result of external facility-related heating. While testing at the highest beam current and voltage, one of the thermocouples on a cylindrical magnet ring showed excessive heating and exhibited arcing. This was likely due to electrons from the external plasma drifting through the plasma screen and accelerating to the magnets. This was not a form of heating that was accounted for a priori and was notably worse with higher background pressures. Further discussions quantifying this effect based on the discrepancy between the plasma model predictions and the finite difference model are presented in the next section. This effect led not only to a noticeable increase in heating, but also resulted in greater asymmetric heating than predicted by the model due to differing open area fractions of plasma screen, which affected the local electron current. 
TABLE 2.-COMPARISON OF THE TEMPERATURES OF TDT (REF. 12) TO THE MODEL FOR 1.2 A BEAM CURRENT

\begin{tabular}{|c|c|c|c|c|c|c|}
\hline Beam voltage $(\mathrm{V})$ & \multicolumn{2}{|l|}{679} & \multicolumn{2}{|l|}{1179} & \multicolumn{2}{|l|}{1800} \\
\hline Beam current $(\mathrm{A})$ & \multicolumn{2}{|l|}{1.2} & \multicolumn{2}{|l|}{1.2} & \multicolumn{2}{|l|}{1.2} \\
\hline \multirow[t]{2}{*}{ Discharge power (W) } & \multicolumn{2}{|l|}{271} & \multicolumn{2}{|l|}{243} & \multicolumn{2}{|l|}{234} \\
\hline & $\begin{array}{l}\text { TDT } \\
{ }^{\mathrm{a}}\left({ }^{\circ} \mathrm{C}\right) \\
\end{array}$ & $\begin{array}{c}\text { Model } \\
\left({ }^{\circ} \mathrm{C}\right) \\
\end{array}$ & $\begin{array}{l}\text { TDT } \\
{ }^{\mathrm{a}}\left({ }^{\circ} \mathrm{C}\right) \\
\end{array}$ & $\begin{array}{c}\text { Model } \\
\left({ }^{\circ} \mathrm{C}\right) \\
\end{array}$ & $\begin{array}{l}\text { TDT } \\
{ }^{\mathrm{a}}\left({ }^{\circ} \mathrm{C}\right) \\
\end{array}$ & $\begin{array}{c}\text { Model } \\
\left({ }^{\circ} \mathrm{C}\right) \\
\end{array}$ \\
\hline Front magnet ring & 171,166 & 169 & 161,166 & 167 & 162,167 & 167 \\
\hline Cylindrical magnet ring & 133,143 & $135-145$ & 134,146 & 134-143 & 139,163 & $144-155$ \\
\hline Conical magnet ring & 150,151 & 147 & 142,146 & 141 & 144,147 & 141 \\
\hline Cathode magnet ring & 172 & $171-172$ & 168 & $168-170$ & 168 & $169-170$ \\
\hline Discharge chamber cutout & $130,132,137,146$ & 133 & $132,133,141,143$ & 132 & $140,142,147,150$ & 141 \\
\hline Upstream harness & 101 & 105 & 102 & 99 & 107 & 106 \\
\hline Downstream harness & 107 & 97 & 107 & 96 & 112 & 100 \\
\hline Propellant isolator & 86 & 88 & 85 & 87 & 87 & 92 \\
\hline Cathode tube & 432 & 412 & 426 & 409 & 424 & 408 \\
\hline Cathode sputter shield & 157 & 161 & 155 & 159 & 155 & 160 \\
\hline Optics mounting ring & 112 & 109 & 111 & 106 & 116 & 109 \\
\hline Screen grid support & 150 & 147 & 143 & 140 & 145 & 142 \\
\hline Accelerator grid support & 101 & 106 & 99 & 103 & 107 & 107 \\
\hline Cathode harness support & 124 & & 121 & & 122 & \\
\hline Neutralizer keeper & 547 & 546 & 548 & 546 & 553 & 546 \\
\hline Neutralizer support & 89 & 85 & 89 & 85 & 91 & 89 \\
\hline Mask optics edge & 63,47 & $55-60$ & 63,47 & $55-60$ & 50,66 & $57-63$ \\
\hline Middle mask & 48 & 52 & 48 & 53 & 52 & 55 \\
\hline Plasma screen cyl/mask & 76,52 & $52-72$ & 52,76 & $52-73$ & 56,78 & $54-76$ \\
\hline Gimbal pads & $91,89,91$ & 88 & $91,89,92$ & 87 & $92,93,97$ & 92 \\
\hline Plasma screen con/cyl & 71,63 & $61-64$ & 63,71 & $61-65$ & 68,73 & $65-69$ \\
\hline Exit wire harness & 70 & 67 & 69 & 66 & 71 & 69 \\
\hline Plasma screen rear & 62 & 55 & 62 & 56 & 64 & 57 \\
\hline
\end{tabular}

${ }^{\mathrm{a}}$ Multiple TDT values indicate thermocouple readings at different azimuthal locations. 
TABLE 3.-COMPARISON OF THE TEMPERATURES OF TDT (REF. 12) TO THE MODEL FOR 2.0 AND 3.52 A BEAM CURRENTS

\begin{tabular}{|c|c|c|c|c|c|c|}
\hline Beam Voltage (V) & \multicolumn{2}{|l|}{1179} & \multicolumn{2}{|l|}{1179} & \multicolumn{2}{|l|}{1800} \\
\hline Beam Current (A) & \multicolumn{2}{|l|}{2.0} & \multicolumn{2}{|l|}{3.52} & \multicolumn{2}{|l|}{3.52} \\
\hline Discharge Power (W) & \multicolumn{2}{|l|}{335} & \multicolumn{2}{|l|}{475} & \multicolumn{2}{|l|}{434} \\
\hline & $\begin{array}{l}\text { TDT } \\
{ }^{\mathrm{a}}\left({ }^{\circ} \mathrm{C}\right) \\
\end{array}$ & $\begin{array}{c}\text { Model } \\
\left({ }^{\circ} \mathrm{C}\right) \\
\end{array}$ & $\begin{array}{l}\text { TDT } \\
{ }^{\mathrm{a}}\left({ }^{\circ} \mathrm{C}\right) \\
\end{array}$ & $\begin{array}{c}\text { Model } \\
\left({ }^{\circ} \mathrm{C}\right) \\
\end{array}$ & $\begin{array}{r}\text { TDT } \\
{ }^{\mathrm{a}}\left({ }^{\circ} \mathrm{C}\right) \\
\end{array}$ & $\begin{array}{c}\text { Model } \\
\left({ }^{\circ} \mathrm{C}\right) \\
\end{array}$ \\
\hline Front magnet ring & 200 & 199 & 241 & 245 & 242 & 249 \\
\hline Cylindrical magnet ring & 164 & $168-182$ & 203,239 & $213-231$ & 212,261 & $227-248$ \\
\hline Conical magnet ring & 169,174 & 165 & 213,215 & 213 & 214,214 & $215-216$ \\
\hline Cathode magnet ring & 190 & 190-191 & 227 & $231-233$ & 227 & $228-231$ \\
\hline Discharge chamber cutout & $164,170,170,175$ & 165 & $196,198,215,210$ & 207 & $209,209,216,222$ & 221 \\
\hline Upstream harness & 121 & 116 & 165 & 178 & 178 & 184 \\
\hline Downstream harness & 127 & 121 & 171 & 156 & 183 & 172 \\
\hline Propellant isolator & 100 & 106 & 139 & 138 & 142 & 146 \\
\hline Cathode tube & 448 & 429 & 474 & 460 & 471 & 459 \\
\hline Cathode sputter shield & 170 & 171 & 200 & 197 & 203 & 197 \\
\hline Optics mounting ring & 133 & 128 & 171 & 168 & 175 & 173 \\
\hline Screen grid support & 172 & 165 & 221 & 217 & 223 & 221 \\
\hline Accel grid support & 120 & 126 & 161 & 169 & 164 & 174 \\
\hline Cathode harness support & 140 & & 178 & & 179 & \\
\hline Neutralizer keeper & 544 & 547 & 558 & 563 & 558 & 563 \\
\hline Neutralizer support & 102 & 101 & 136 & 130 & 143 & 137 \\
\hline Mask optics edge & 59,75 & $68-73$ & 88,101 & 94-99 & 92,106 & $100-104$ \\
\hline Middle mask & 60 & 65 & 88 & 90 & 92 & 96 \\
\hline Plasma screen cyl/mask & 66,89 & $64-85$ & 98,119 & $94-110$ & 103,124 & $95-115$ \\
\hline Gimbal pads & $107,108,110$ & 106 & $145,146,153$ & 138 & $150,152,163$ & 146 \\
\hline Plasma screen con/cyl & 76,83 & $74-78$ & 94,96 & $106-108$ & 124,124 & $112-114$ \\
\hline Exit wire harness & 83 & 79 & 97 & 114 & 129 & 119 \\
\hline Plasma screen rear & 68 & 62 & 86 & 90 & 106 & 97 \\
\hline
\end{tabular}

${ }^{\mathrm{a}}$ Multiple TDT values indicate thermocouple readings at different azimuthal locations. 
For all cases presented here, the a priori plasma power deposition values were used as initial estimates of heating from the discharge plasma on the thruster. The heating on the anode was evenly distributed between the magnet rings. These values were then adjusted to obtain agreement with the test data. The power deposition that was used corresponding to the temperatures shown in Table 2 and Table 3 are given in Table 4 and Table 5, respectively.

Two observations can be made comparing the a priori estimate of heating to those used to replicate the testing. The first is that with greater beam current and voltage, a larger amount of heating was required over the predictions to duplicate the test temperatures. This is likely due to the previously mentioned heating from facility plasma and is described in further detail in the next section. This could mean that at $3.52 \mathrm{~A}$ and $1800 \mathrm{~V}$, there was an additional $123 \mathrm{~W}$ of heating occurring from the background plasma.

TABLE 4.-POWER DEPOSITION PREDICTED FROM PLASMA MODEL ALONG WITH DEPOSITION USED IN FINITE DIFFERENCE MODEL TO MATCH TEST TEMPERATURES SHOWN IN TABLE 2

\begin{tabular}{|l|c|c|c|c|c|c|c|c|c|}
\cline { 2 - 9 } \multicolumn{1}{c|}{} & \multicolumn{3}{c|}{$1.2 \mathrm{~A} / 679 \mathrm{~V}$} & \multicolumn{3}{c|}{$1.2 \mathrm{~A} / 1179 \mathrm{~V}$} & \multicolumn{3}{c|}{$1.2 \mathrm{~A} / 1800 \mathrm{~V}$} \\
\cline { 2 - 10 } \multicolumn{1}{c|}{} & $\begin{array}{c}\text { Pred. } \\
\text { (W) }\end{array}$ & $\begin{array}{c}\text { Used } \\
(\mathrm{W})\end{array}$ & $\begin{array}{c}\% \text { of } \\
\text { pred. }\end{array}$ & $\begin{array}{c}\text { Pred. } \\
(\mathrm{W})\end{array}$ & $\begin{array}{c}\text { Used } \\
(\mathrm{W})\end{array}$ & $\begin{array}{c}\% \text { of } \\
\text { pred. }\end{array}$ & $\begin{array}{c}\text { Pred. } \\
(\mathrm{W})\end{array}$ & $\begin{array}{c}\text { Used } \\
(\mathrm{W})\end{array}$ & $\begin{array}{c}\% \text { of } \\
\text { pred. }\end{array}$ \\
\hline Cathode magnet ring & 18 & 3 & 17 & 16 & 3 & 19 & 15 & 3 & 20 \\
Conical magnet ring & 51 & 55.8 & 110 & 45 & 49.7 & 110 & 44 & 47.7 & 110 \\
Cylindrical magnet ring & 84 & 124.2 & 148 & 75 & 122 & 164 & 72 & 140.0 & 194 \\
Front magnet ring & 82 & 47 & 57 & 73 & 45.9 & 63 & 70 & 44.3 & 63 \\
Total anode & 235 & 230 & 98 & 209 & 221 & 106 & 201 & 235 & 117 \\
DCA keeper & 5.1 & 5.1 & 100 & 5.0 & 5.0 & 100 & 5.0 & 5.0 & 100 \\
Screen grid & 9.9 & 22 & 222 & 9.4 & 18.9 & 201 & 9.3 & 18.9 & 203 \\
Accelerator grid & 4.5 & 4 & 89 & 4.5 & 4 & 89 & 4.9 & 4.9 & 100 \\
DCA insert tip temp & 1008 & 1008 & 100 & 1001 & 1001 & 100 & 998 & 998 & 100 \\
\hline
\end{tabular}

TABLE 5.-POWER DEPOSITION PREDICTED FROM PLASMA MODEL ALONG WITH DEPOSITION USED IN FINITE DIFFERENCE MODEL TO MATCH TEST TEMPERATURES SHOWN IN TABLE 3

\begin{tabular}{|l|c|c|c|c|c|c|c|c|c|}
\cline { 2 - 9 } & \multicolumn{3}{c|}{$2.0 \mathrm{~A} / 1179 \mathrm{~V}$} & \multicolumn{3}{c|}{$3.52 \mathrm{~A} / 1179 \mathrm{~V}$} & \multicolumn{3}{c|}{$3.52 \mathrm{~A} / 1800 \mathrm{~V}$} \\
\cline { 2 - 10 } & $\begin{array}{c}\text { Pred. } \\
\text { (W) }\end{array}$ & $\begin{array}{c}\text { Used } \\
\text { (W) }\end{array}$ & $\begin{array}{c}\text { \% of } \\
\text { pred. }\end{array}$ & $\begin{array}{c}\text { Pred. } \\
\text { (W) }\end{array}$ & $\begin{array}{c}\text { Used } \\
(\mathrm{W})\end{array}$ & $\begin{array}{c}\text { \% of } \\
\text { pred. }\end{array}$ & $\begin{array}{c}\text { Pred. } \\
(\mathrm{W})\end{array}$ & $\begin{array}{c}\text { Used } \\
\text { (W) }\end{array}$ & $\begin{array}{c}\text { \% of } \\
\text { pred. }\end{array}$ \\
\hline Cathode magnet ring & 21 & 5 & 23 & 29 & 10 & 34 & 27 & 8 & 29 \\
Conical magnet ring & 60 & 65.5 & 109 & 82 & 100 & 122 & 77 & 100 & 129 \\
Cylindrical magnet ring & 100 & 180 & 180 & 136 & 250 & 184 & 128 & 285 & 223 \\
Front magnet ring & 97 & 62 & 64 & 132 & 87.1 & 66 & 124 & 87.1 & 70 \\
Total anode & 278 & 313 & 112 & 379 & 447 & 118 & 356 & 480 & 135 \\
DCA keeper & 6.9 & 6.9 & 100 & 11.5 & 11.5 & 100 & 11.4 & 11.4 & 100 \\
Screen grid & 16.9 & 24 & 142 & 31.0 & 39 & 126 & 29.7 & 39 & 131 \\
Accelerator grid & 9.0 & 9.0 & 100 & 20.7 & 20 & 97 & 20.2 & 20.7 & 102 \\
DCA insert tip temp & 1035 & 1035 & 100 & 1063 & 1063 & 100 & 1057 & 1057 & 100 \\
\hline
\end{tabular}


A second observation can be made from the comparison of data to modeling. The relative amount of heating to the magnet rings does not appear to be based purely on the length of the magnet ring footprint around the circumference. The percent of power added at each magnet ring from the predicted amount is fairly consistent for all of the cases except at the cylindrical magnet rings. The cylindrical magnet rings were in the region that exhibited electrons penetrating the plasma screen from the background plasma. If this effect is subtracted out, the ratio of heating to the various magnet rings remains fairly constant at 0.1:1:2:1 for the cathode-to-conical-to-cylindrical-to-front magnet rings over the throttling range examined. This is quite different than the ratio of plasma heating that is based on the magnet rings footprint of 0.2:0.6:1:1. This would indicate that the cylindrical magnet rings receive the largest amount of current from the discharge plasma, followed by the conical and front magnet rings. There would then be virtually no current collected back by the cathode magnet rings. The mission analysis presented here will use the 0.1:1:2:1 ratio for the hottest case mission predictions. The heating in those cases correspond to the $3.52 \mathrm{~A}$ and $1179 \mathrm{~V}$ throttling point with the exception that the cylindrical heat flux will be $200 \mathrm{~W}$ instead of $250 \mathrm{~W}$, which includes the facility plasma effect.

\section{Facility Effects on Thermal Measurements}

As previously mentioned, there was a facility-related effect that provided additional heating to the thruster. This effect became more pronounced at the higher beam voltages and currents. This heating was a result of external plasma electrons drifting through the plasma screen, being accelerated to the anode and then following the magnetic field lines to the magnets. The external plasma density decreases from the exit plane of the thruster to its upstream side (Ref. 21). As a result, this heating effect was most pronounced on thermocouples in the cylindrical region of the thruster near the exit plane. It was these thermocouples that registered the largest temperature increases (see Tables 2 and 3). These temperature increases were counter to the decreasing discharge power and heating that occurs as the beam voltage increases at a fixed beam current.

It is important to quantify this effect in order to determine the amount of heating that a thruster will experience in a vacuum facility versus a spaceflight mission. Figure 9 shows the amount of power used at the magnet rings in the modeling of the thermal development test as a percentage of the total predicted anode internal plasma power deposition. At the lowest beam current and voltage, the total anode power applied was essentially equal to the predicted amount. As the beam current and voltage increase, the percent of power used for the cathode, conical and front magnet rings remains fairly constant. The increase in applied power primarily comes at the cylindrical magnet rings. It does not appear that the internal plasma is redistributing itself during these throttling changes since the power at all of the noncylindrical magnet rings is constant. Therefore, it appears that the increase is primarily due to the external plasma. At $3.52 \mathrm{~A}$ and $1800 \mathrm{~V}$, this heating is 134 percent of the predicted value. This translates into about $120 \mathrm{~W}$ of additional heating. This could be accounted for by as little as $68 \mathrm{~mA}$ of electrons being accelerated through $1800 \mathrm{~V}$. This would be processed by the beam power supply and only represents 2 percent of the measured beam current, which would be difficult to discern during testing. It is important to realize that this effect is a result of the background plasma and, hence, the background pressure. During testing of the NEXT PM1 thruster in a larger vacuum facility (NASA Glenn VF6), which operated with a lower background pressure, the anomalous change in the magnet temperatures was less pronounced as the beam voltage increased (Ref. 22). In that test, the two different cylindrical magnet ring temperatures changed by $-3{ }^{\circ} \mathrm{C}$ and $+9{ }^{\circ} \mathrm{C}$ when increasing in beam voltage from $1179 \mathrm{~V}$ to $1800 \mathrm{~V}$ at $3.52 \mathrm{~A}$ beam current. During the TDT, as can be seen from Table 3, these same thermocouples locations changed by $+9{ }^{\circ} \mathrm{C}$ and $+22^{\circ} \mathrm{C}$. A rigorous thermal model was not done to quantify the effect on the testing in VF6, but based on an evaluation of the temperature changes at different throttling points, it would be expected that these backstreaming electrons represent $<1$ percent of the measured beam current. Because of concern that this facility effect could overheat critical thruster components, the NEXT PM thruster design now has a solid panel around the cylindrical region and the open area fraction was reduced from 50 to 20 percent in the conical region. The thermal effect of that design change is predicted in the following section. 


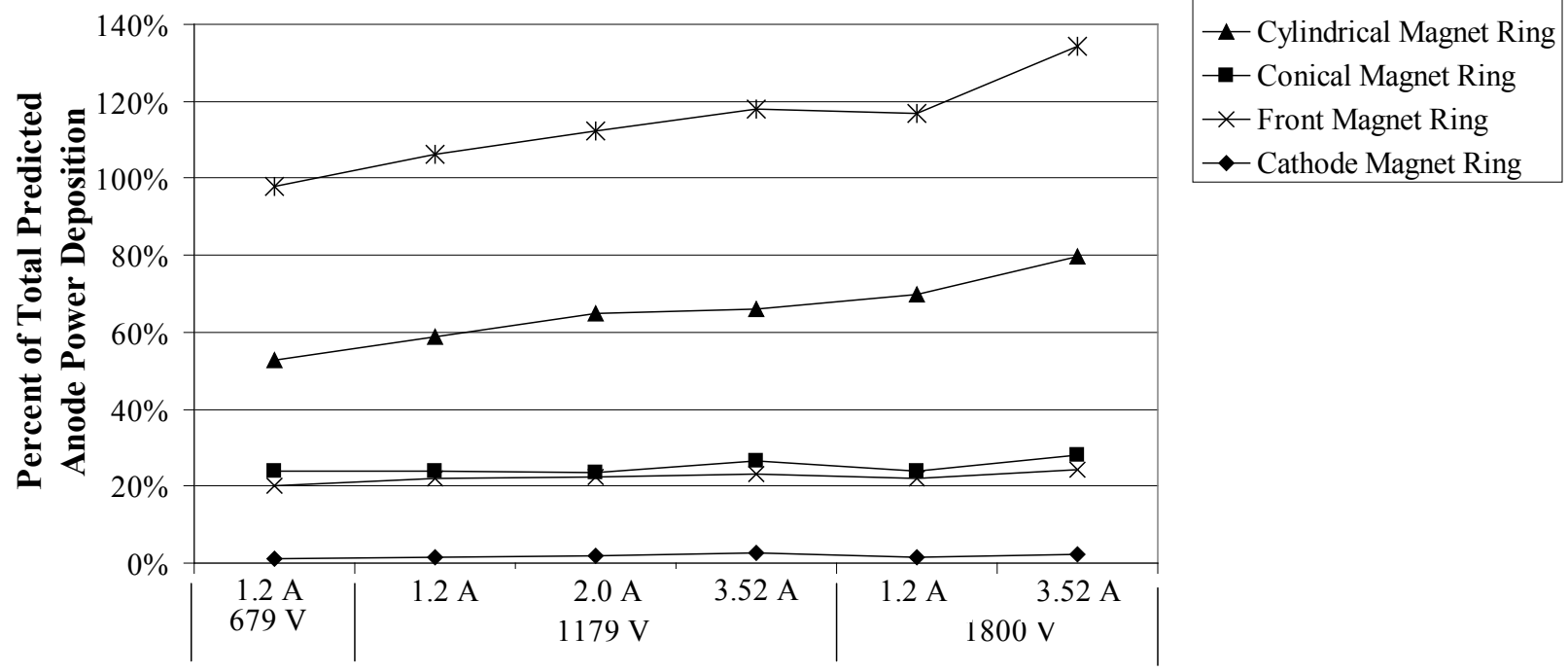

Figure 9.-Trend showing the percent of power deposition to the magnet ring or anode out of the total predicted anode power deposition for various throttling points.

\section{Prediction of PM Thruster Temperatures for Hottest Case Anticipated from Potential Missions}

It is necessary to model the ion thruster under the hottest expected thermal environment to ensure that all of its components have sufficient thermal margin for operation. The NEXT PM thruster currently does not yet have a spaceflight application. However, a deep space design reference mission (DSDRM) was derived from the study of spaceflight applications using the NEXT ion thruster. For those DSDRM, the maximum environmental heating occurred at $0.85 \mathrm{AU}$, when the sun angle was $38^{\circ}$ off the thruster axis (Ref. 23).

The spacecraft interface is critical to the thermal modeling effort. Currently, there is no spacecraft interface defined since there is no application. Based on the previous ion thruster missions of Deep Space One and Dawn, it is conservative to assume that the thruster will be mounted in an adiabatic can (Refs. 24 and 25). This adiabatic can will have to encompass the gimbal footprint and likely extend downstream as far as the gimbal interface. Any further would probably interfere with gimbal articulation. Generally, the smaller the gap between the thruster and the can, the hotter the thruster will be. It is also possible that a mission using the NEXT thruster will include multiple thrusters. The most conservative case to model is one thruster in an adiabatic can acting as a mirror to all incident heat that encapsulates its gimbal footprint with minimal gap. Figure 10 shows the comparison of a can around one thruster versus three thrusters. The solid lines indicate a line of symmetry for the multiple thrusters and could be modeled as a single thruster with an adiabatic surface along that line to model its view to space. This demonstrates that modeling a single thruster in a small adiabatic can would allow for much less of the thruster to view, and hence radiate to, space. That is, the single thruster in the smallest adiabatic can will produce the highest temperatures. The case modeled here is shown in Figure 11. 


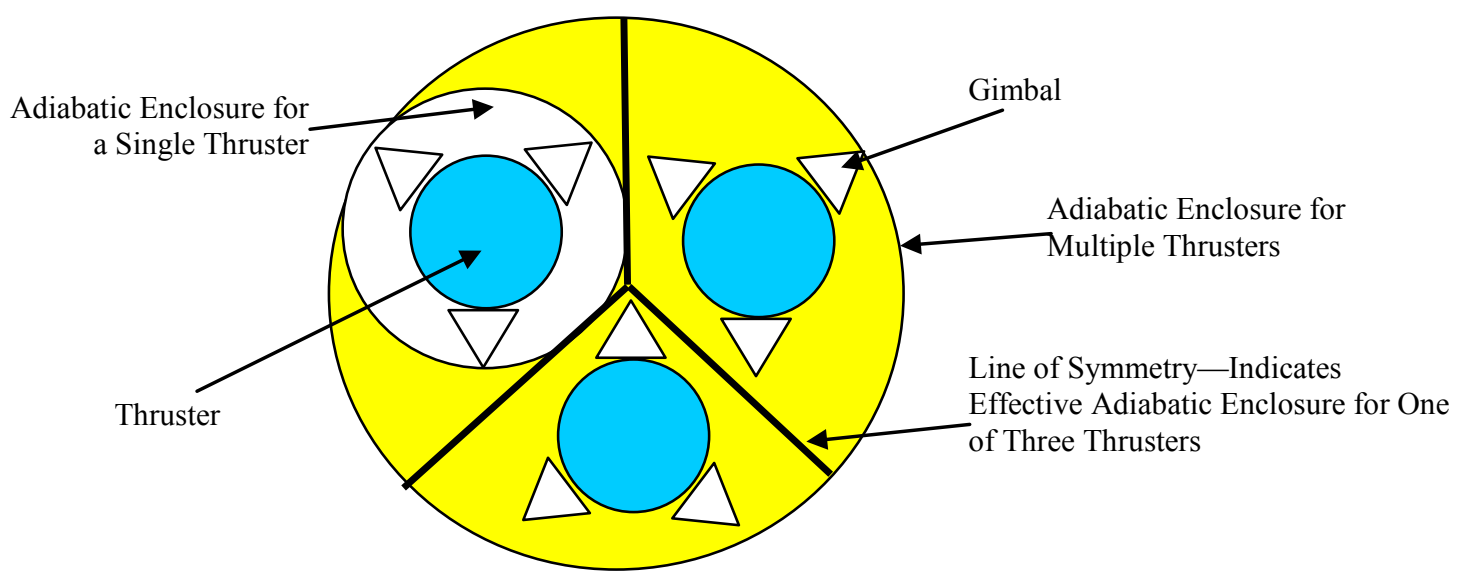

Figure 10.-Image showing the comparison of the envelope of one thruster versus three thrusters.

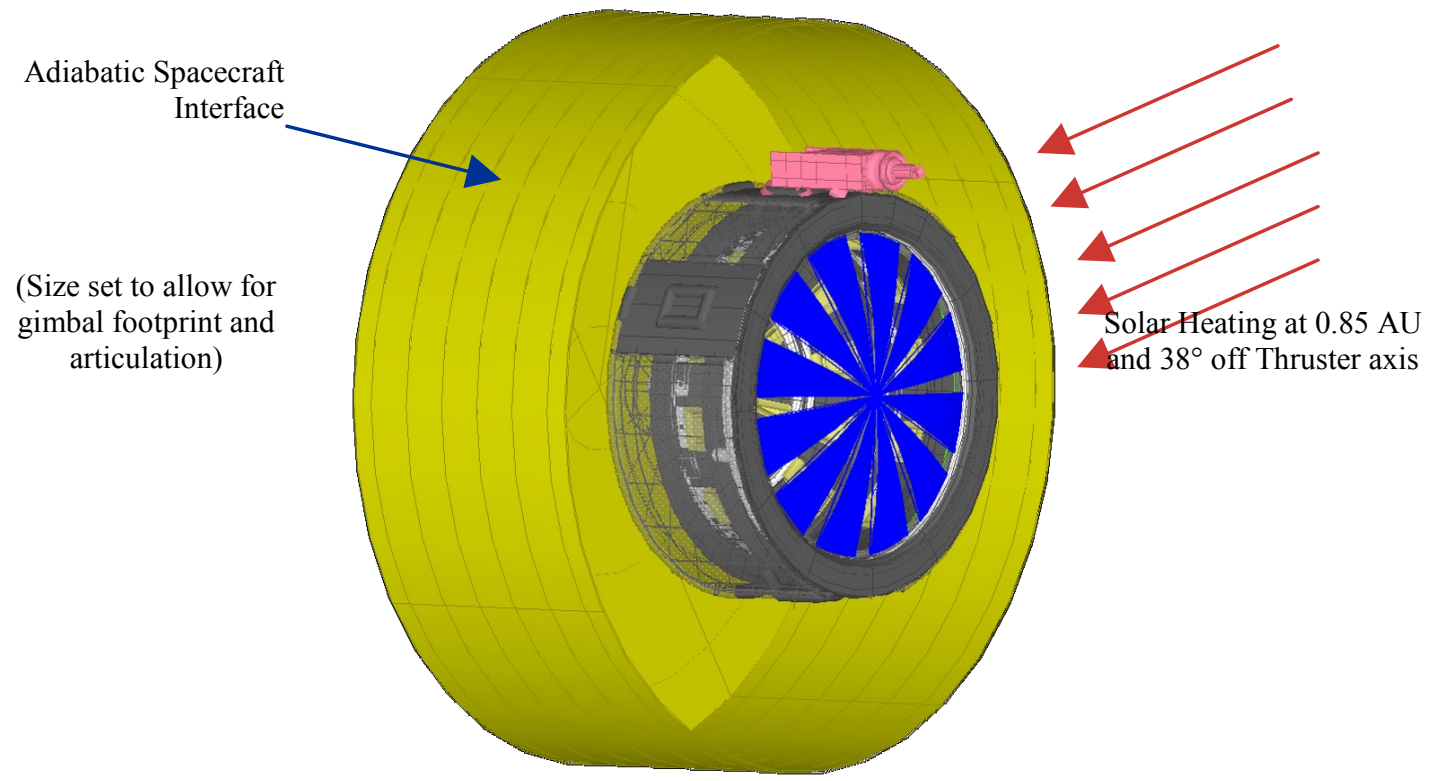

Figure 11.-Image depicting the model of the spacecraft interface for highest mission temperatures.

The largest amount of heating from the internal plasma corresponds to the highest beam current and lowest beam voltage. For this thruster that would be $3.52 \mathrm{~A}$ beam current and $1179 \mathrm{~V}$ beam voltage. The heating values that were used in this model are the same as those shown in Table 3 for the TDT at $3.52 \mathrm{~A}$ and $1179 \mathrm{~V}$ except that the cylindrical magnet rings received $200 \mathrm{~W}$ instead of the $250 \mathrm{~W}$ that included the facility plasma heating. Two cases were modeled under the same internal and environmental heating. One case modeled the plasma screens with an open area of 50 percent as found on PM1 during the TDT. The second case modeled represents the revised PM design with a solid plasma shield in the cylindrical region and a 20 percent open area plasma screen in the conic portion. The result of the 50 percent open area plasma screen is shown in Figure 12. The second case would look quite comparable because the temperatures shifted somewhat uniformly with a maximum shift of only around $+10{ }^{\circ} \mathrm{C}$. Table 6 contains the maximum temperature for several of the thruster components along with component margin for both cases. There is margin for all thruster components with the exception of the external harness leaving the thruster. Presently, the harness is rated only to $150^{\circ} \mathrm{C}$. However, during the TDT, the harness reached $192{ }^{\circ} \mathrm{C}$ without any observable damage. The cable is currently under investigation for re-rating or replacement, otherwise, the thermal design of the NEXT thruster is sufficient for the DSDRM. 


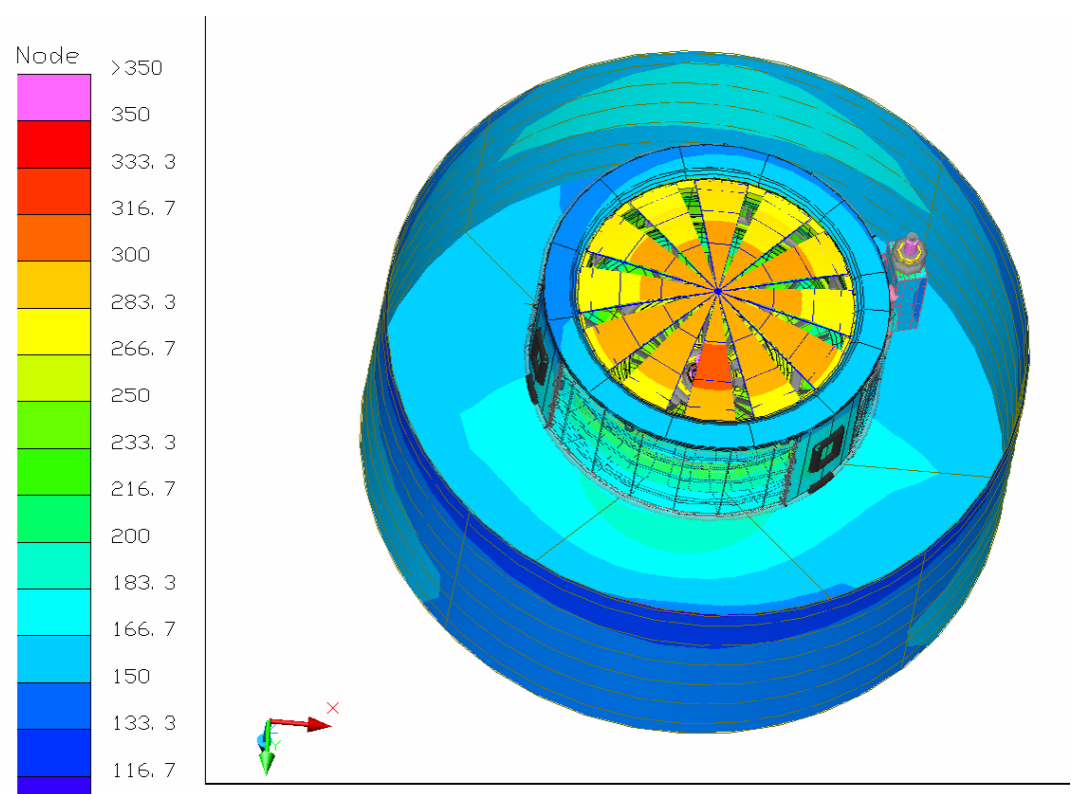

100

$<100$

Temperature $[C]$, Time $=0$ sec

Figure 12.-An image showing the thruster temperatures predicted for the hottest case mission and operation.

TABLE 6.-A TABLE CONTAINING THE MAXIMUM PREDICTED TEMPERATURES AND MARGINS FOR KEY COMPONENTS WITH TWO DIFFERENT PLASMA SCREEN SCHEMES

\begin{tabular}{|c|c|c|c|c|c|}
\hline Beam voltage & \multirow{5}{*}{$\begin{array}{l}\text { Maximum } \\
\text { allowable } \\
\text { temperature }\end{array}$} & $1179 \mathrm{~V}$ & \multirow[t]{5}{*}{ Margin } & $1179 \mathrm{~V}$ & \multirow[t]{5}{*}{ Margin } \\
\hline Beam current & & $3.52 \mathrm{~A}$ & & $3.52 \mathrm{~A}$ & \\
\hline Discharge power & & $475 \mathrm{~W}$ & & $475 \mathrm{~W}$ & \\
\hline${ }^{\mathrm{a} C}$ Cylindrical plasma screen OAF & & $50 \%$ & & $0 \%$ & \\
\hline${ }^{\mathrm{a} C}$ Conical plasma screen OAF & & $50 \%$ & & $20 \%$ & \\
\hline Front magnet ring & $360{ }^{\circ} \mathrm{C}$ & $279^{\circ} \mathrm{C}$ & $\geqq 81{ }^{\circ} \mathrm{C}$ & $286^{\circ} \mathrm{C}$ & $\geqq 74{ }^{\circ} \mathrm{C}$ \\
\hline Cylindrical magnet ring & $360{ }^{\circ} \mathrm{C}$ & $239-255^{\circ} \mathrm{C}$ & $\geqq 105^{\circ} \mathrm{C}$ & $250-266^{\circ} \mathrm{C}$ & $\geqq 94^{\circ} \mathrm{C}$ \\
\hline Conical magnet ring & $360^{\circ} \mathrm{C}$ & $257-258^{\circ} \mathrm{C}$ & $\geqq 102{ }^{\circ} \mathrm{C}$ & $264-265^{\circ} \mathrm{C}$ & $\geqq 95^{\circ} \mathrm{C}$ \\
\hline Cathode magnet ring & $360^{\circ} \mathrm{C}$ & $280-283{ }^{\circ} \mathrm{C}$ & $\geqq 77^{\circ} \mathrm{C}$ & $286-288^{\circ} \mathrm{C}$ & $\geqq 72^{\circ} \mathrm{C}$ \\
\hline Propellant isolator & $265^{\circ} \mathrm{C}$ & $187^{\circ} \mathrm{C}$ & $\geqq 78^{\circ} \mathrm{C}$ & $195^{\circ} \mathrm{C}$ & $\geqq 70^{\circ} \mathrm{C}$ \\
\hline Optics harness & $260{ }^{\circ} \mathrm{C}$ & $193^{\circ} \mathrm{C}$ & $\geqq 67{ }^{\circ} \mathrm{C}$ & $210^{\circ} \mathrm{C}$ & $\geqq 50^{\circ} \mathrm{C}$ \\
\hline Titanium mounting ring & $\mathrm{b}$ & $211-275^{\circ} \mathrm{C}$ & $\mathrm{b}$ & $223-276{ }^{\circ} \mathrm{C}$ & $\mathrm{b}$ \\
\hline Screen grid support & $\mathrm{b}$ & $251-270{ }^{\circ} \mathrm{C}$ & $\mathrm{b}$ & $259-270{ }^{\circ} \mathrm{C}$ & $\mathrm{b}$ \\
\hline Accel grid support & $\mathrm{b}$ & $267-304^{\circ} \mathrm{C}$ & $\mathrm{b}$ & $276-305^{\circ} \mathrm{C}$ & $\mathrm{b}$ \\
\hline Gimbal pads & $\mathrm{b}$ & $132-187^{\circ} \mathrm{C}$ & $\mathrm{b}$ & $141-195{ }^{\circ} \mathrm{C}$ & $\mathrm{b}$ \\
\hline Exit wire harness & $150^{\circ} \mathrm{C}$ & $194^{\circ} \mathrm{C}$ & ${ }^{\mathrm{c}}-44^{\circ} \mathrm{C}$ & $199^{\circ} \mathrm{C}$ & ${ }^{\mathrm{c}}-49^{\circ} \mathrm{C}$ \\
\hline
\end{tabular}

${ }^{\mathrm{a}} \mathrm{OAF}=$ open area fraction

${ }^{\mathrm{b}}$ Margin well exceeds $100^{\circ} \mathrm{C}$

${ }^{c}$ Harness currently rated to $150{ }^{\circ} \mathrm{C}$, program is proceeding by either re-rating or replacing the harness 


\section{Conclusion}

A thermal model has been presented that predicts the heating from the plasma on the NEXT thruster and the temperatures of the thruster under various environmental and operating conditions. Plasma heating was predicted primarily using a discharge chamber plasma model. This model is based on measured performance voltages and currents from a thruster. It predicts power deposition to the anode, discharge keeper, screen grid, accelerator grid, and cathode. Input parameters with a degree of uncertainty, such as ion loss area, are varied such that the predicted discharge losses are equal to the measured discharge power. These power deposition predictions are then used as inputs in a NEXT thruster thermal model. This thermal model uses commercially available finite difference thermal software.

Critical plasma self-heating values and contact resistances were adjusted to match the thermal data taken during the thermal development test. Besides the model's primary purpose to predict the thruster temperatures, another determination from the model included a facility heating effect from a small current of background plasma electrons penetrating the plasma screen and heating the anode. This effect is a function of the facility background pressure.

It was determined that the heating and current collection to the anode magnet rings is not purely related to the footprint of the magnet rings. If the current collection and related heating to the anode was equally distributed based on the magnet ring footprints, the relative amount of power deposition would be 0.2:0.6:1:1 for the cathode-to-conical-to-cylindrical-to-front magnet rings. However, after subtracting out the facility heating effects, the ratio of heating the model requires was $0.1: 1: 2: 1$. This indicates that the current density collection is not equal at the respective magnet rings, with the cylindrical magnet ring collecting the highest density. This also demonstrates the added uncertainty of the ion and electron loss area.

The thermal model predicts most thermocouple temperatures within $10^{\circ} \mathrm{C}$ for several throttling points during the thermal development test. When the thermal model is used to predict the temperatures from a worst case mission scenario, the temperature margin for all but the external wire harness is greater than $50^{\circ} \mathrm{C}$. The temperature of the wire harness exiting the thruster currently exceeds its rating, so the cable is under investigation for re-rating or replacement to provide sufficient margin. Aside from the cable, the thermal design of the NEXT thruster has ample thermal margin. 


\section{Appendix A.-Symbols List}

$A_{a n} \quad$ anode surface area, $\mathrm{m}^{2}$

$A_{d c} \quad$ surface area of discharge chamber, $\mathrm{m}^{2}$

$A_{g} \quad$ area of ion grids, $\mathrm{m}^{2}$

$A_{h a} \quad$ hybrid anode area (electron loss area at cusp), $\mathrm{m}^{2}$

$A_{i} \quad$ ion loss area, $\mathrm{m}^{2}$

$A_{\text {ins cs }} \quad$ insert cross sectional area, $\mathrm{m}^{2}$

$A_{k} \quad$ area of keeper face, $\mathrm{m}^{2}$

$A_{R} \quad$ Richardson's coefficient, $60 \mathrm{~A} / \mathrm{cm}^{2} \mathrm{~K}^{2}$ (for tungsten)

$A_{s a} \quad$ surface area of anode, $\mathrm{m}^{2}$

$d A \quad$ differential surface area of insert, $\mathrm{m}^{2}$

$d x \quad$ differential axial length of insert, $\mathrm{m}$

$e \quad$ elementary charge, $1.60 \times 10^{-19} \mathrm{C}$

$f_{c} \quad$ fraction of Bohm current to anode $\left(I_{a n}{ }^{+} / I_{\text {Bohm }}\right)$, fraction

$I_{B} \quad$ beam current, $\mathrm{A}$

$I_{D} \quad$ discharge current, $\mathrm{A}$

$I_{a g}{ }^{+} \quad$ accelerator grid ion current, $\mathrm{A}$

$I_{a n}{ }^{m-} \quad$ Maxwellian electron current collected by anode, A

$I_{a n}^{p-} \quad$ primary electron current collected by anode, A

$\mathrm{I}_{a n}{ }^{+} \quad$ ion current to anode, A

$I_{c}^{+} \quad$ ions to cathode insert surface, A

$I_{e} \quad$ cathode emission current, A

$I_{\text {ins }} \quad$ insert thermionic emission, A

$I_{k}^{+} \quad$ keeper ion current, A

$I_{k}^{-} \quad$ electron current to keeper, A

$I_{l}^{+} \quad$ discharge plasma ion loss rate, A

$\mathrm{I}_{m-}{ }^{+} \quad$ ions from Maxwellian electron collisions, A

$I_{n}{ }^{*} \quad$ excitation of neutrals, equiv. A

$\mathrm{I}_{p l}{ }^{+} \quad$ total ions produced from electron collisions, A

$\mathrm{I}_{p-}{ }^{+} \quad$ ions via primary electron collisions, A

$I_{s g} \quad$ screen grid current, A

$I_{s g}{ }^{+} \quad$ screen grid ion current, A

$I_{s g}{ }^{-} \quad$ screen grid electron current, A

$I_{+}{ }^{*} \quad$ excitation of ions, equiv. A

$k \quad$ Boltzmann constant, $1.38 \times 10^{-23} \mathrm{~J} / \mathrm{K}$

$K_{\text {ins }} \quad$ thermal conductivity of insert, $\mathrm{W} / \mathrm{m} \mathrm{K}$

$L_{p-} \quad$ average primary electron path length to anode, $\mathrm{m}$

$\dot{m} \quad$ mass flow rate, $\mathrm{sccm}$

$M_{e} \quad$ electron mass, $9.11 \times 10^{-31} \mathrm{~kg}$

$M_{X e} \quad$ mass of xenon atom, $2.18 \times 10^{-25} \mathrm{~kg}$ 


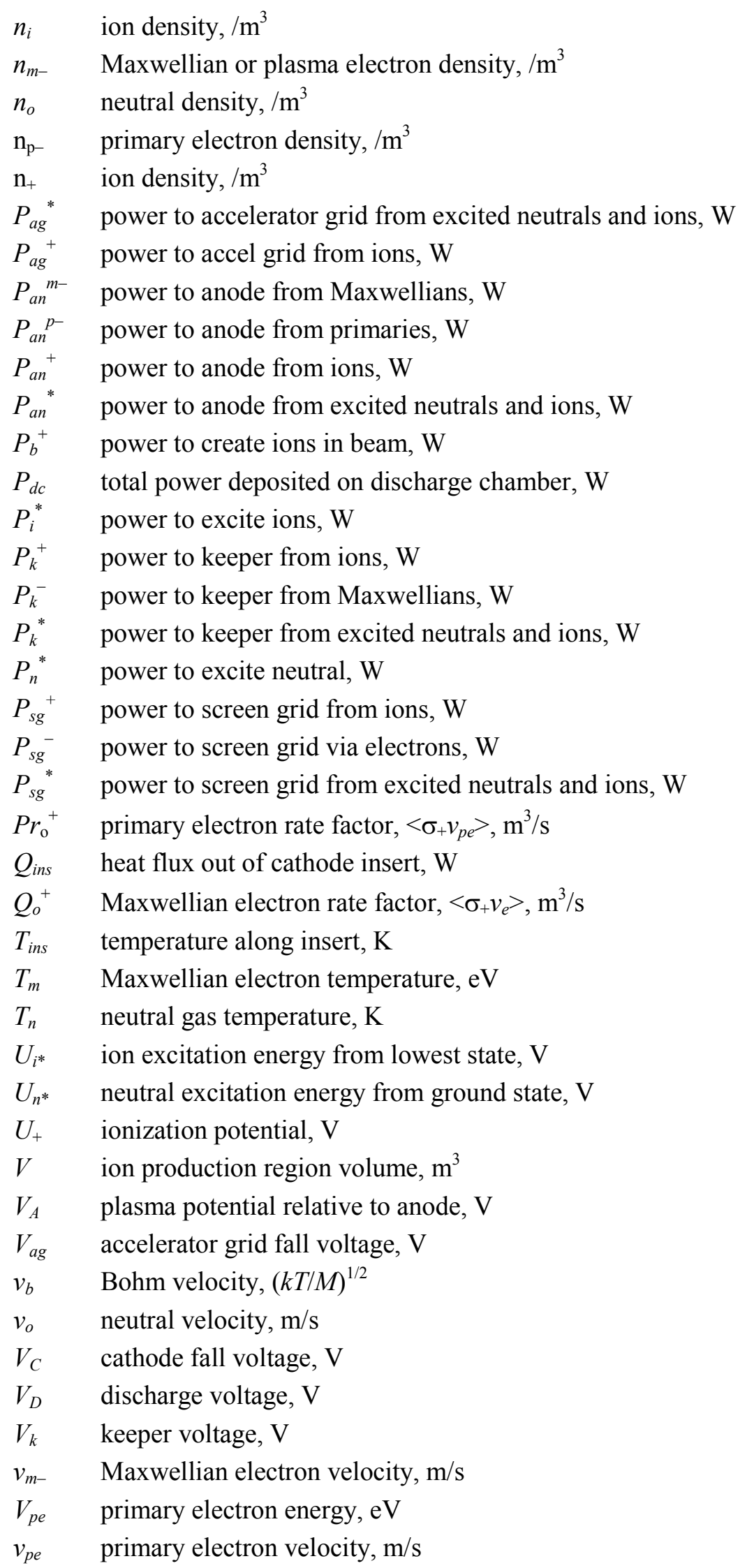




$\begin{array}{ll}\eta_{c} & \text { clausing factor, fraction } \\ \eta_{m} & \text { mass utilization, fraction } \\ \sigma_{p^{*}} & \text { primary neutral excitation cross sectional area, } \mathrm{m}^{2} \\ \sigma_{p^{+*}} & \text { primary-ion excitation cross sectional area, } \mathrm{m}^{2} \\ \sigma_{T} & \text { total }\left(\sigma_{+}+\sigma_{p}^{*}\right) \text { cross sectional area, } \mathrm{m}^{2} \\ \sigma_{+} & \text {ionization cross sectional area, } \mathrm{m}^{2} \\ \phi_{a n} & \text { anode work function, eV } \\ \Phi_{i} & \text { screen grid ion transparency, fraction } \\ \phi_{i n s} & \text { insert work function, eV } \\ \phi_{k} & \text { keeper work function, eV } \\ \phi_{s g} & \text { screen grid work function, eV } \\ \phi_{a g} & \text { accelerator grid work function, eV } \\ \Phi_{a g o} & \text { accelerator grid open area fraction, fraction } \\ \Phi_{s g o} & \text { screen grid open area fraction, fraction } \\ \Omega_{k} & \text { anode to keeper resistance, Ohms }\end{array}$




\section{References}

1. Wen, L., Crotty, J.D., and Pawlik, E.V., "Ion Thruster Thermal Characteristics and Performance," Journal Spacecraft and Rockets, Vol. 10, No. 1, Jan. 1973, pp. 35-41.

2 Oglebay, J.C., "Thermal Analytical Model of a $30 \mathrm{~cm}$ Engineering Model Mercury Ion Thruster," NASA Technical Memorandum, NASA TM X-71680, Mar. 1975.

3. Mirtich, M.J., "The Effects of Exposure to $\mathrm{LN}_{2}$ Temperatures and 2.5 Suns Solar Radiation on 30-cm Ion Thruster Performance," NASA Technical Memorandum, NASA TM X-71652.

4. Mirtich, M. J., "Thermal-Environment Testing of a 30-cm Engineering Model Thruster," NASA Technical Memorandum, NASA TM X-73522, Nov. 1976.

5. Bechtel, R. T., and Dulgeroff, C. R., "J Series Thruster Thermal Test Results," AIAA 82-1906, 16 International Electric Propulsion Conference, New Orleans, LA, Nov. 1982.

6. Van Noord, J., Gallimore, A., and Rawlin, V., "Numerical thermal Model of a 30-cm NSTAR Ion Thruster," IEPC 97-185, 25th International Electric Propulsion Conference, Cleveland, OH, Aug. 1997.

7. Sovey, J. S., et al., "Development of an Ion Thruster and Power Processor for New Millennium's Deep Space 1 Mission," AIAA 1997-2778, 33rd AIAA joint Propulsion Conference, Seattle, WA, Jul. 1997.

8. Rawlin, V., Patterson, M., and Becker, R., "Thermal Environmental Testing of NSTAR Engineering Model Ion Thruster," IEPC 97-051, 25th International Electric Propulsion Conference, Cleveland, OH, Aug. 1997.

9. Christensen, J.A., et al., "Design and Fabrication of a Flight Model $2.3 \mathrm{~kW}$ Ion Thruster for the Deep Space 1 Mission," AIAA 1998-3327, 34th AIAA Joint Propulsion Conference, Cleveland, OH, Jul. 1998.

10. Van Noord, J., Gallimore, A., and Rawlin, V., "Numerical Thermal Model of NASA Solar Electric Propulsion Technology Application Readiness Ion Thruster," Journal of Propulsion and Power, Vol. 16, No. 2, 2000, pp. 357-364.

11. Sarver-Verhey, T.R., Domonkos, M.T., and Patterson, M.J., "Thermal Characterization of a NASA 30cm Ion Thruster Operated up to 5 kW," AIAA-2000-36943, 36th AIAA Joint Propulsion Conference, Huntsville, AL, Jul. 2000.

12. Anderson, J. A., Snyder, J. S., Van Noord, J. L., and Soulas, G. C., "Thermal Development Test of the NEXT PM1 Ion Engine," AIAA-2007-5217, 43rd AIAA Joint Propulsion Conference, Cincinnati, OH, Jul. 2007.

13. Brophy, J.R., "Ion Thruster Performance Model," Ph.D. Dissertation, Colorado State Univ., Fort Collins, CO, also NASA CR-174810, Dec. 1984.

14. Goebel, D.M., Wirz, R.E., and Katz, I., "Analytical Ion Thruster Discharge Performance Model," AIAA-2006-4486,

15. Van Noord, J.L., "Thermal Modeling of an Ion Thruster," Ph.D. Dissertation, University of Michigan, Ann Arbor, MI, also NASA/CR - 2000-209792, Feb. 2000.

16. Chapman, B., Glow Discharge Processes, John Wiley\& Sons, Inc., New York, NY, 1980.

17. Rapp, D., Englander-Golden, P., "Total Cross Sections for Ionization and Attachment in Gases by Electron Impact. I. Positive Ionization," Journal of Chemical Physics, Vol. 34, No. 5, 1965, pp. 581-589.

18. Domonkos, M.T., Foster, J.E., and Soulas, G.C., "Wear Testing and Analysis of Ion Engine Discharge Cathode Keeper," Journal of Propulsion and Power, Vol. 21, No. 1, 2005, pp. 102-110.

19. Van Noord, J.L., Kamhawi, H., and McEwen, H.K., "Characterization of a High Current Long Life Hollow Cathode," IEPC-2005-321, 29th International Electric Propulsion Conference, Princeton, NJ, Nov. 2005, also NASA/TM-2006-214095.

20. Herman, D.A., "The Use of Electrostatic Probes to Characterize the Discharge Plasma Structure and Identify Discharge Cathode Erosion Mechanisms in Ring-Cusp Ion Thrusters," Ph.D. Dissertation, University of Michigan, Ann Arbor, MI, 2005.

21. McEwen, H., Foster, J., Patterson, M., Pencil, E., and Diaz, E., "Characterization of Plasma Flux Incident on Multi-Thruster Array," AIAA-2006-5183, 42nd AIAA Joint Propulsion Conference, Sacramento, CA, Jul. 2006. 
22. Herman, D., Soulas, G., and Patterson, M., "Performance Evaluation of the 40-cm NEXT Prototype Model Ion Thruster," 43rd Joint Propulsion Conference and Exhibit, AIAA-2007-5212, Cincinnati, OH, Jul. 8-11, 2007.

23. Hoskins, W.A., Wilson, F.C., Polaha, J., Talerico, L., Patterson, M.J., Soulas, G.C., and Sovey, J., "Development of a Prototype Model Ion Thruster for the NEXT System," AIAA-2004-4111, 40th AIAA Joint Propulsion Conference, Ft. Lauderdale, FL, Jul. 2004.

24. Davis, V.A., Katz, I., Mandell, M.J., Brinza, D.E., Henry, M.D., Wang, J.J., Young, D.T, “Ion Generated Charge Exchange Environment: Comparison Between NSTAR Flight Data and Numerical Simulations," AIAA-2000-3529, 36th AIAA joint Propulsion Conference, Huntsville, AL, Jul. 2000.

25. Brophy, J. R., et al., "Development and Testing of Dawn Ion Propulsion System," AIAA-2006-4319, 42nd AIAA Joint Propulsion Conference, Sacramento, CA, Jul. 2006. 


\begin{tabular}{|c|c|c|}
\hline \multicolumn{2}{|c|}{ REPORT DOCUMENTATION PAGE } & $\begin{array}{l}\text { Form Approved } \\
\text { OMB No. 0704-0188 }\end{array}$ \\
\hline \multicolumn{3}{|c|}{ 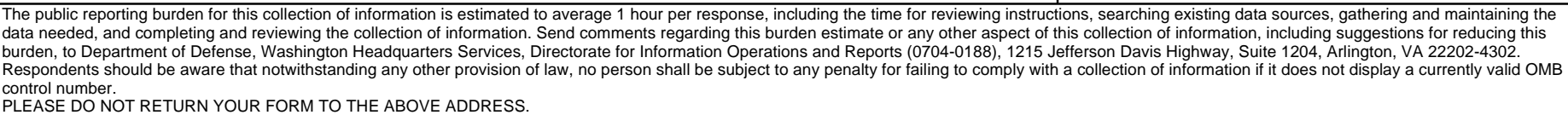 } \\
\hline $\begin{array}{l}\text { 1. REPORT DATE (DD-MM-YYYY) } \\
01-11-2010\end{array}$ & $\begin{array}{l}\text { 2. REPORT TYPE } \\
\text { Technical Memorandum }\end{array}$ & 3. DATES COVERED (From - To) \\
\hline \multirow{3}{*}{\multicolumn{2}{|c|}{$\begin{array}{l}\text { 4. TITLE AND SUBTITLE } \\
\text { NEXT Ion Thruster Thermal Model }\end{array}$}} & 5a. CONTRACT NUMBER \\
\hline & & 5b. GRANT NUMBER \\
\hline & & 5c. PROGRAM ELEMENT NUMBER \\
\hline \multirow{3}{*}{\multicolumn{2}{|c|}{$\begin{array}{l}\text { 6. AUTHOR(S) } \\
\text { Van Noord, Jonathan, L. }\end{array}$}} & 5d. PROJECT NUMBER \\
\hline & & 5e. TASK NUMBER \\
\hline & & $\begin{array}{l}\text { 5f. WORK UNIT NUMBER } \\
\text { WBS 346620.04.05.03.13 }\end{array}$ \\
\hline \multicolumn{2}{|c|}{$\begin{array}{l}\text { 7. PERFORMING ORGANIZATION NAME(S) AND ADDRESS(ES) } \\
\text { National Aeronautics and Space Administration } \\
\text { John H. Glenn Research Center at Lewis Field } \\
\text { Cleveland, Ohio 44135-3191 }\end{array}$} & $\begin{array}{l}\text { 8. PERFORMING ORGANIZATION } \\
\text { REPORT NUMBER } \\
\text { E-17495 }\end{array}$ \\
\hline \multirow{2}{*}{\multicolumn{2}{|c|}{$\begin{array}{l}\text { 9. SPONSORING/MONITORING AGENCY NAME(S) AND ADDRESS(ES) } \\
\text { National Aeronautics and Space Administration } \\
\text { Washington, DC 20546-0001 }\end{array}$}} & $\begin{array}{l}\text { 10. SPONSORING/MONITOR'S } \\
\text { ACRONYM(S) } \\
\text { NASA }\end{array}$ \\
\hline & & $\begin{array}{l}\text { 11. SPONSORING/MONITORING } \\
\text { REPORT NUMBER } \\
\text { NASA/TM-2010-216919 }\end{array}$ \\
\hline \multicolumn{3}{|c|}{$\begin{array}{l}\text { 12. DISTRIBUTION/AVAILABILITY STATEMENT } \\
\text { Unclassified-Unlimited } \\
\text { Subject Category: } 20 \\
\text { Available electronically at http://gltrs.grc.nasa.gov } \\
\text { This publication is available from the NASA Center for AeroSpace Information, 443-757-5802 }\end{array}$} \\
\hline
\end{tabular}

\section{SUPPLEMENTARY NOTES}

\section{ABSTRACT}

As the NEXT ion thruster progresses towards higher technology readiness, it is necessary to develop the tools that will support its implementation into flight programs. An ion thruster thermal model has been developed for the latest prototype model design to aid in predicting thruster temperatures for various missions. This model is comprised of two parts. The first part predicts the heating from the discharge plasma for various throttling points based on a discharge chamber plasma model. This model shows, as expected, that the internal heating is strongly correlated with the discharge power. Typically, the internal plasma heating increases with beam current and decreases slightly with beam voltage. The second is a model based on a finite difference thermal code used to predict the thruster temperatures. Both parts of the model will be described in this paper. This model has been correlated with a thermal development test on the NEXT Prototype Model 1 thruster with most predicted component temperatures within 5 to $10{ }^{\circ} \mathrm{C}$ of test temperatures. The model indicates that heating, and hence current collection, is not based purely on the footprint of the magnet rings, but follows a 0.1:1:2:1 ratio for the cathode-to-conical-tocylindrical-to- front magnet rings. This thermal model has also been used to predict the temperatures during the worst case mission profile that is anticipated for the thruster. The model predicts ample thermal margin for all of its components except the external cable harness under the hottest anticipated mission scenario. The external cable harness will be re-rated or replaced to meet the predicted environment. 15. SUBJECT TERMS Ion engines; Plasmas (physics)

\begin{tabular}{|c|c|c|c|c|c|}
\hline \multicolumn{3}{|c|}{ 16. SECURITY CLASSIFICATION OF: } & \multirow{2}{*}{$\begin{array}{l}\text { 17. LIMITATION OF } \\
\text { ABSTRACT } \\
\text { UU }\end{array}$} & \multirow{2}{*}{$\begin{array}{l}\text { 18. NUMBER } \\
\text { OF } \\
\text { PAGES } \\
33\end{array}$} & \multirow{2}{*}{$\begin{array}{l}\text { 19a. NAME OF RESPONSIBLE PERSON } \\
\text { STI Help Desk (email:help@sti.nasa.gov) } \\
\text { 19b. TELEPHONE NUMBER (include area code) } \\
\text { 443-757-5802 }\end{array}$} \\
\hline $\begin{array}{l}\text { a. REPORT } \\
\text { U }\end{array}$ & $\begin{array}{l}\text { b. ABSTRACT } \\
\mathrm{U}\end{array}$ & $\begin{array}{l}\text { c. THIS } \\
\text { PAGE } \\
\text { U }\end{array}$ & & & \\
\hline
\end{tabular}



